\title{
Francia y la España del tardofranquismo y la transición. Sinergias económicas en un marco de cambio político, 1970-1986*
}

\author{
Esther M. Sánchez Sánchez \\ Universidad de Salamanca \\ esther.sanchez@usal.es
}

RESUMEN: La doble crisis, política y económica, de los años setenta se dejó sentir en las relaciones franco-españolas, que desde finales de los años cincuenta habian avanzado por la vía del entendimiento. El proceso de cambio de régimen en España provocó sonados enfrentamientos entre ambos países, sobre todo en torno a la lucha contra la organización terrorista ETA y el futuro ingreso de España en el Mercado Común. Las relaciones económicas bilaterales evolucionaron, no obstante, de forma satisfactoria pese a la crisis política española y la crisis energética mun-

* Esta investigación ha contado con el apoyo financiero del Ministerio de Economía y Competitividad (proyectos HAR2012-33298 y HAR2015-64769-P) y de la Universidad de Salamanca (proyecto KA7A/463AC01). Las primeras versiones del texto se discutieron en el VI Congreso de la Asociación de Historiadores del Presente (Madrid-Valladolid, marzo 2014) y en el XVI Seminario de Historia Económica de las Universidades Complutense, UNED, Valladolid y Salamanca (Bernardos, junio 2014). Agradezco los comentarios y sugerencias de los relatores Adoración Álvaro y Rafael Castro, así como los de los evaluadores anónimos de Hispania. La generosidad de Rafael Castro a la hora de compartir información y recursos merece una mención muy especial. Naturalmente, solo yo soy responsable de los errores e insuficiencias que permanezcan en esta versión final. Siglas utilizadas: Archives du Ministère Français des Affaires Étrangères (AMAE-F), Archivo del Ministerio Español de Asuntos Exteriores (AMAE-E), Centre des Archives Économiques et Financières-France (CAEF); Archives Nationales-Centre des Archives Contemporaines-France (AN-CAC); Direction de l'Europe-Sous-direction d'Europe Méridionale del Ministerio Francés de Asuntos Exteriores (MAE-SDEM), Direction des Affaires Économiques et Financières del Ministerio Francés de Asuntos Exteriores (MAE-DAEF); Direction des Relations Culturelles, Scientifiques et Techniques del Ministerio Francés de Asuntos Exteriores (MAE-DRCST). Los términos «Alemania» $\mathrm{y}$ «RFA» se emplean indistintamente para aludir a la República Federal de Alemania. Las citas textuales se han conservado en su idioma original. 
dial, arrojando valores al alza en materia de comercio, planes de inversión y cooperación científico-técnica. El objetivo de este trabajo es analizar tales desencuentros políticos y encuentros económicos, a partir de un conjunto de fuentes impresas y fondos de archivo, en su mayoría franceses, recientemente abiertos a los investigadores.

\section{PALABRAS ClAVE: Francia; España; Tardofranquismo; Transición a la Democracia; Relaciones Franco-Españolas.}

France and Spain during the Late Francoism and Transition. Economic Synergies withing a Framework of Political Charge, 1970-1986

ABSTRACT: French-Spanish relations, which had made considerable progress since the end of the Fifties, were affected by the political and economic crisis of the Seventies. The process of regime change in Spain caused notorious confrontations between the two countries, mainly focused on the fight against the terrorist organization ETA and the Spain's future membership in the Common Market. However, bilateral economic relations evolved in a satisfactory way despite both the Spanish political and the worldwide energy crisis, providing growing numbers in trade, investment plans and scientifictechnical cooperation. The aim of this paper is to explore such political disconnections and economic connections, from a set of printed sources and archival records, mostly French, recently opened to researchers.

KEY WORDS: France; Spain; Late-Francoism; Transition to Democracy; French-Spanish Relations.

En los años setenta y principios de los ochenta, las relaciones francoespañolas pasaron por uno de sus momentos de mayor distanciamiento. Los desencuentros en torno a la lucha contra Euskadi Ta Askatasuna (ETA) y la adhesión de España a la Comunidad Económica Europea (CEE) marcaron unos años complejos, en los que resurgieron muchas de las tensiones y hostilidades del pasado. Ahora bien, los enfrentamientos políticos apenas influyeron en la cooperación económica, que se materializó en numerosos proyectos bilaterales en las esferas comercial, financiera y científico-técnica. Las autoridades españolas sabían que su proceso de modernización e integración europea pasaba de forma inevitable (que no exclusiva) por Francia, y sus homólogas francesas continuaban guiándose por el principio de no adoptar ninguna actitud drástica que, como ocurrió con el cierre fronterizo de 1946-48, pudiera volver a poner en peligro sus intereses económicos en España.

A finales de los setenta, a pesar de la férrea competencia ejercida por otros países (sobre todo Estados Unidos y la República Federal de Alemania-RFA), el capital francés se hallaba sólidamente implantado en España, ocupando un lugar preferente en sectores tan emblemáticos como el automóvil, la construcción, la consultoría técnica, la banca y la gran distribución. En el intento 
de expandir su actividad en España, los agentes económicos franceses libraron una dura batalla con sus rivales extranjeros y modificaron, aún sin pretenderlo, su modelo tradicional de inversión industrial en beneficio del sector terciario. ¿Cuáles fueron las líneas básicas de la acción francesa hacia España? ¿Qué protagonistas, estrategias y resultados destacaron? ¿Influyó, de alguna manera, el cambio político español sobre la evolución de las relaciones económicas bilaterales? Este trabajo pretende contribuir a esclarecer estas cuestiones, analizando en prioridad la dimensión económica a partir de un conjunto de fuentes impresas y archivísticas, en su mayoría francesas, recientemente abiertas a los investigadores. La documentación utilizada procede de fondos gubernamentales, por lo que la perspectiva estatal prevalece sobre las demás. Ello no implica, empero, restar importancia a actores no estatales que, como los empresarios privados, desempeñaron un papel fundamental en los procesos y acontecimientos analizados.

La estructura del texto es la siguiente: un primer apartado repasa el estado, histórico e historiográfico, de las relaciones franco-españolas en los años finales del franquismo y primeros de la democracia; el segundo se centra en los dos grandes contenciosos del período: el terrorismo vasco y el ingreso de España en el Mercado Común europeo; en el tercero, se aborda la trayectoria de las relaciones económicas bilaterales, examinando la evolución de comercio e inversión, y evocando algunos de los principales proyectos de cooperación. El cuarto estudia las estrategias desplegadas por las autoridades francesas para reforzar su presencia económica al otro lado de los Pirineos, así como el grado de cumplimiento de esos objetivos gubernamentales. Cierran el trabajo unas breves conclusiones.

\section{LAS RELACIONES FRANCO-ESPAÑOLAS EN UN ESCENARIO DE CRISIS}

La historiografía sobre la transición española se ha enriquecido enormemente en los últimos años. Aunque los primeros estudios adoptaron enfoques endógenos, insistiendo en el protagonismo de las élites políticas locales y en el apoyo de agentes económicos y sociales también autóctonos, desde los años noventa comenzó a despuntar la variable internacional, incrementándose los trabajos sobre el papel de Estados Unidos y las potencias europeas: Francia, la RFA y, en menor medida, Gran Bretaña ${ }^{1}$. Los especialistas coinciden al señalar que los países occidentales se atribuyeron un papel de supervisión y tutela sobre la transición española. Con un doble objetivo: por un lado, garan-

1 La actitud de Gran Bretaña resultó condicionada por la cuestión de Gibraltar y la tradición anti-franquista de los laboristas, lo que a la larga situaría a Londres en clara desventaja respecto a París y Bonn. MARTÍN GARCÍA, LXXII/242 (Madrid, 2010): 170-171. 
tizar un proceso gradual, controlado y pacífico, evitando el fortalecimiento de los extremos; y por otro, ocupar un lugar de peso en la nueva España postfranquista. Estados Unidos y Europa occidental compartían el temor a la «portugalización» de la transición española, es decir que el proceso se radicalizase con el ascenso de los comunistas y el consiguiente fortalecimiento de la ultraderecha, degenerando en un clima de guerra civil con consecuencias nefastas a nivel nacional e internacional. De ahí que los líderes occidentales dirigieran sus miras hacia los elementos reformistas de dentro y fuera del régimen franquista, promocionaran la monarquía parlamentaria como elemento de estabilidad y normalización, e intensificaran las relaciones con sectores que, como el Ejército y los empresarios, podían influir sobre el gobierno y defender más y mejor los intereses extranjeros en España (de tipo político, económico y/o geoestratégico). Además, las potencias occidentales utilizaron los instrumentos culturales, informativos y propagandísticos de la diplomacia pública, con la intención de crear un clima de opinión favorable a sus sistemas políticos y económicos ${ }^{2}$.

Salvo excepciones, y a pesar de la oposición de las fuerzas de izquierda, los gobiernos europeos y norteamericano habían negociado con Franco con relativa comodidad y sin ningún cargo de conciencia, concluyendo numerosos acuerdos en los ámbitos comercial, financiero, militar, cultural y científicotécnico. No obstante, también habían configurado una sólida red de relaciones con los grupos e individuos que estaban destinados a suceder al dictador, tanto entre los elementos reformistas del propio régimen (desde la administración hasta la empresa privada) ${ }^{3}$ como entre los partidos y sindicatos de la

2 Sobre el proceso de transición española a la democracia, y en particular su vertiente exterior, pueden consultarse los trabajos de POWELL, 1994; 2001; 2003; 2011. GILLESPIE, RODRIGO y STORY, 1995. TUSELL y SOTO, 1996. PEREIRA, 2001; 2004. LEMUS, 2002; 2005; 2007. VIÑAS, 2003. PARDO, 2005. SOTO, 2005. ORTUÑO, 2005. JIMÉNEZ, 2006; 2009. SARTORIUS y SABIO, 2007; 2011. GUIRAO, 2007. POWELL y JIMÉNEZ, 2007. LEMUS y PEREIRA, 2010. MARTÍN GARCÍA y ORTIZ HERAS, 2010. PERO, GAVÍN, GUIRAO y VARSORI, 2010. SANZ, 2012. RODRÍGUEZ, DELGADO y CULL, 2015. Damián González Madrid ha publicado una síntesis historiográfica en MARTÍN GARCÍA y ORTIZ HERAS, 2010: 39-61. Los libros de memorias de los protagonistas del proceso resultan un complemento imprescindible, entre ellos AREILZA, 1977. CARRILLO, 1983. FRAGA, 1987. MORÁN LÓPEZ, 1990. CALVO-SOTELO, 1990; 1999. LÓPEZ RODÓ, 1993. BASSOLS, 1995. En conjunto, los estudios dedicados específicamente a Francia resultan aún sesgados y superficiales, en buena medida por basarse en prensa y no en fuentes de archivo, v.g. ACUÑA, 1986. GONZÁLEZ-GÓMEZ DEL MIÑO, 1991. BUSTURIA, 1994. VORMS y AGUILAR, 2003. MESTRES, 2006. PINILLA, 2013.

3 Muchas veces encarnados en las mismas personas. En Francia y en España existían vínculos muy estrechos entre la administración pública y la alta gestión empresarial, siendo habitual encontrar los mismos nombres en uno y otro ámbito. Vid., entre otros, GARRIGUES, 2011. JOLY, 2013 para el caso de Francia. Y BAENA, 1999. CABRERA y DEL REY, 2002. VALDALISO, 2002 para el caso de España. 
oposición moderada (el PSOE y la UGT, fundamentalmente) ${ }^{4}$. Esos contactos resultarían decisivos en la nueva etapa democrática.

¿Cómo evolucionaron las relaciones políticas entre España y Francia a finales del franquismo y principios de la democracia? Durante los gobiernos de Georges Pompidou (gaullista, 1969-1974), Valéry Giscard d'Estaing (centroderecha, 1974-1981) y el primer mandato de François Mitterrand (socialista, 1981-1988) se sucedieron las etapas de acercamiento y distanciamiento ${ }^{5}$, y por tanto el repunte periódico del arsenal de estereotipos, prejuicios y rencores mutuos acumulados durante siglos ${ }^{6}$. Como las demás potencias occidentales, Francia rechazó la vía revolucionaria y concibió el tándem monarquíaoposición moderada como la mejor fórmula para conservar sus posiciones en la España posterior a Franco ${ }^{7}$. Cualquier radicalismo, fuese del color que fuese, desmantelaría unas parcelas de influencia que había llevado décadas, e incluso siglos, conquistar ${ }^{8}$.

En las postrimerías de la dictadura, los responsables franceses manifestaron repetidamente su voluntad de no aprobar ninguna disposición extrema que, como a finales de los años cuarenta, perjudicase gravemente sus intereses en España: «[Il faut] pratiquer une politique plus reservée vis-à-vis du régime, plus ouverte en direction de l'oposition modérée, mais conservatoire pour tout ce qui, à court terme, touche à nos intérêts, en particulier à la coopération» ${ }^{9}$. Ni siquiera las últimas decisiones represivas de Franco (el proceso de Burgos contra los integrantes de ETA en 1970, la ejecución del joven anarquista Salvador Puig Antich en 1974 y los últimos fusilamientos de septiembre de 1975), que desataron la condena de la sociedad francesa e interna-

4 La socialdemocracia alemana se convirtió en la principal impulsora de la política de colaboración entre los socialistas europeos. MUÑOZ SÁNCHEZ, 2012: 148. Interesa consultar, además, ORTUÑO, 2005. AROCA, 2011. SOTO y MATEOS, 2013. BERNECKER, 2013.

5 Resulta muy ilustrativo a este respecto el título del trabajo publicado en 1986 por el periodista Luis Ramón Acuña: Como los dientes de una sierra. ACUÑA, 1986.

6 Con los calificativos «clásicos»: los franceses: arrogantes, racionales y egoístas; los españoles: orgullosos, resentidos y dramáticos. Sobre cuestiones de imagen, sugerimos la lectura de ANGOUSTURES, 37 (París, 1990). MARTÍNEZ-VASSEUR, 24 (Cáceres, 1997). PELLISTRANDI, 2001. DÍAZ y MARTÍNEZ-VASSEUR, 2003. LUIS y NIÑO, 2004.

7 Tanto el futuro rey como los dirigentes de la oposición moderada habían manifestado personalmente al presidente, ministros y prensa progubernamental francesa (Le Figaro, L'Aurore, La Croix) su voluntad reformista y su apuesta por un cambio ordenado y «sin sobresaltos». «Entretien avec le Prince Juan Carlos», nota de Georges Roux, consejero técnico de la Embajada de Francia en España, Madrid, 16/11/1976. AMAE-F, Europe, Espagne, 197176, vol. 446; y «De la visite du roi d'Espagne en France», informe del MAE-SDEM, París, 9/9/1976. AMAE-F, Europe, Espagne, 1976-80, vol. 4394.

8 POWELL: 1994: 90-91.

9 «Suggestion quant à notre attitude vis-à-vis de l'Espagne», informe del MAE-SDEM, París, 19/9/1975. AMAE-F, Europe, Espagne, 1971-76, vol. 446. 
cional, modificaron la actitud del gobierno francés. Desde la Asamblea Nacional se dieron consignas de discreción, amparándose en el principio de la no injerencia en los asuntos internos de otro país, en el interés por mantener las buenas relaciones con España, y en la inoperancia de las medidas radicales tipo ruptura diplomática o bloqueo económico ${ }^{10}$. En noviembre de 1975, el presidente francés Giscard d'Estaing, desoyendo las críticas de los partidos de oposición, la prensa de izquierda y buena parte de la sociedad francesa, colocó a media asta las banderas de los edificios oficiales en señal de duelo por el dictador, y asistió a la ceremonia de entronización del rey Juan Carlos como signo de apoyo a la sucesión monárquica. El nombramiento de Adolfo Suárez como presidente del gobierno en julio de 1976 también recibió, superada la sorpresa inicial, el beneplácito del gobierno francés, sobre todo tras el anuncio de su proyecto de reforma política.

La crisis económica mundial acrecentó las debilidades de la transición española. Las consecuencias del shock energético (1973-74 y 1978-79) y del hundimiento del sistema monetario de Bretton Woods (1971) resultaron especialmente graves para las economías francesa y española, altamente dependientes del petróleo y con una elevada inflación previa ${ }^{11}$. Ahora bien, aunque las tasas de inflación, paro y déficit exterior crecieron en ambos países, sus efectos fueron mucho más devastadores para la economía española, dado su menor grado de desarrollo, los desequilibrios estructurales heredados del franquismo y la política económica adoptada por los primeros gobiernos de la transición. Las autoridades francesas aplicaron de inmediato mecanismos de ajuste. Para disminuir la dependencia energética, fomentaron la producción y el consumo de energía nuclear (Plan Messmer de 1974), lo que condujo a un crecimiento espectacular de las centrales nucleares (de 8.000 a 30.000 MW de potencia instalada), y de otras infraestructuras relacionadas con el ciclo atómico (reactores supergeneradores, fábricas de enriquecimiento de uranio, centros para el tratamiento de residuos). Para corregir el desempleo y el déficit exterior, se potenció la creación de industrias de alto contenido tecnológico (telecomunicaciones, informática, biotecnología, aeronáutica, espacial, nuclear), insistiéndose en la necesidad de mantener una estrecha cooperación entre sector público-sector privado, grandes empresas-pymes y universidadindustria. Como otros gobiernos occidentales, el francés procedió a disminuir el intervencionismo estatal, lo que no fue óbice para la abolición de su plani-

10 «Débats de politique étrangère», Assemblée Nationale, 1974-76. AMAE-F, Europe, Espagne, 1971-76, vol. 447.

11 En Francia, el petróleo suponía en torno al 63\% de la energía consumida y la tasa de independencia energética apenas llegaba al 20-25\%. BERSTEIN, CASANOVA y SIRINELLI, 2009: 76. En España, dos terceras partes del consumo energético dependían de las importaciones de crudo. CARRERAS y TAFUNELL, 2005: 408. 
ficación indicativa (6º Plan: 1971-1975, $7^{\circ}$ Plan: 1976-1980 y $8^{\circ}$ Plan: 198185) ni para la reducción del poder de la gran empresa pública (EDF, PTT, SCNF, Renault... $)^{12}$. En España, por el contrario, se reaccionó tarde y mal. La política compensatoria del aumento de los precios del crudo, unida a la protección a la industria pesada y los bajos niveles de $\mathrm{I}+\mathrm{D}$, agravaron enormemente los desequilibrios económicos en un contexto de gran inestabilidad e incertidumbre políticas. Las primeras medidas correctoras llegaron en 1977, de la mano de los Pactos de la Moncloa. Pero la economía española se estancó de nuevo tras la segunda crisis del petróleo y no volvió a la senda del crecimiento hasta bien entrado 1982, efecto de la reconversión industrial y del saneamiento financiero aprobados por el gobierno socialista ${ }^{13}$.

En aquel escenario de crisis, el intercambio de visitas oficiales de altos cargos franceses y españoles, habitual desde los años sesenta, continuó al mismo ritmo. Cabe destacar los viajes a España de los presidentes Valéry Giscard d'Estaing (junio 1978) ${ }^{14}$ y François Mitterrand (junio 1982, junio 1984); los ministros de Asuntos Exteriores Maurice Schumann (noviembre 1971), Michel Jobert (marzo 1974), Louis de Guiringaud (mayo 1978), JeanFrançois Poncet (abril 1980) y Claude Cheysson (junio 1981, mayo 1983); los ministros de Defensa Jacques Soufflet (octubre 1974), Yvon Bourges (octubre 1977) y Charles Hernu (abril 1983); el ministro de Desarrollo Industrial y Científico François-Xavier Ortoli (febrero 1972); el ministro de Industria Michel d'Ornano (junio 1976); el presidente de la Asamblea Nacional Edgar Faure (febrero 1987); el ministro de Comercio Jean-François Deniau (mayo 1978); el ministro de Educación Christian Beullac (noviembre 1978), el Primer ministro Raymond Barré (julio 1980); y el ministro del Interior Gaston Defferre (junio 1984). En los años finales de la dictadura, los representantes franceses evitaron reunirse, al menos públicamente, con los líderes de la oposición anti-franquista, argumentando que en su condición de invitados oficia-

12 Es más, a principios de los años ochenta, se nacionalizarían otros grandes grupos como Péchiney-Ugine Kuhlmann, Thomson-CSF, Saint Gobain, CGE y Rhône-Poulenc. Valéry Giscard d'Estaing, ministro de Economía y Finanzas durante los gobiernos de De Gaulle y Pompidou antes que presidente de la República, hablaba de un «liberalismo avanzado», «liberalismo con componente social» o «liberalismo a la francesa». Vid. JEANNENEY, 1989. LÉVY-LEBOYER, 2006. BARRE, 2007. ABADIE y CORCELETTE, 2009. Y los escritos del propio GISCARD D'ESTAING, 1981; 2004.

13 Entre la abundante literatura sobre la crisis, son trabajos de referencia los de NADAL, CARRERAS y SUDRIÀ, 1987. GARCÍA DELGADO, 1990. CATALAN, 1991. SERRANO, 1994; 2011. HERNÁNDEZ ANDREU, 2004. Una síntesis en CARRERAS y TAFUNELL, 2010.

14 Era el primer presidente de la República francesa en viaje oficial a España desde 1913, año en que Raymond Poincaré visitó a Alfonso XIII. Edouard Herriot realizó una visita oficial a España en 1932, pero no como jefe del estado sino del gobierno; y Charles De Gaulle vino en 1970, pero a título estrictamente privado tras su retirada de la vida pública. 
les del gobierno español habían de adaptarse, por cortesía, a la actitud que sus anfitriones esperaban de ellos ${ }^{15}$. Una actitud análoga a la norteamericana ${ }^{16}$ aunque distinta a la de la RFA, cuyos delegados de Exteriores, y en particular Walter Scheel, intervinieron en varios encuentros con la oposición socialis$\mathrm{ta}^{17}$. Más frecuentes fueron las visitas a Francia de los dirigentes españoles. Francia fue el primer país europeo en recibir a don Juan Carlos y doña Sofía como Reyes de España (octubre 1976) ${ }^{18}$ y el primer destino extranjero de Adolfo Suárez tras su acceso a la cima del ejecutivo (julio 1976). Además de los jefes de estado y de gobierno, los ministros de Asuntos Exteriores, Economía y Defensa, junto a numerosas personalidades relacionadas con la Industria y el Ejército, cruzaron los Pirineos al menos una vez al año ${ }^{19}$. Desde el Quai d'Orsay, se insistió en la necesidad de cuidar al máximo las estancias de los dirigentes españoles en Francia, evitando cualquier alarde de conocimiento y experiencia ante ellos, para no perturbar su más que probada susceptibilidad hacia todo lo que viniera del vecino del norte:

[...] la susceptibilité espagnole vis-à-vis de la France est un problème psychologique fundamental [...] il y a toujours ici le sentiment que les Français considèrent l'Espagne de haut, comme un pays de seconde categorie, et l'on nous en veut [...] on doit faire un effort important pour les recevoir aux mieux» ${ }^{20}$.

$\mathrm{Ni}$ el cambio de régimen en España ni la crisis económica mundial implicaron modificación alguna en las organizaciones de cooperación hispanofrancesa, que continuaron trabajando en sus respectivos ámbitos de actuación. Así lo hicieron la Comisión Internacional de Límites de los Pirineos, el Grupo de Amistad Francia-España de la Asamblea Nacional Francesa, los Comités de Cooperación Industrial y Agraria, el Comité de Cooperación Económica, el Comité de Cooperación Científica y Técnica, y las Comisiones Mixtas ligadas a los Acuerdos Comerciales (anuales), al Acuerdo de Mano de Obra (1961), a la Convención sobre Seguridad Social (1974) y al Acuerdo de Cooperación Cultural, Científica y Técnica (1969, completado en 1974). Además, surgie-

15 Con esos argumentos rechazó expresamente Maurice Schumann el encuentro con los socialistas Enrique Tierno Galván, Carlos Zayas y Miguel Peydro, y con el monárquico Joaquín Satrústegui. «Viaje del ministro Maurice Schumann», informe de la Oficina de Información Diplomática. AMAE-E, R-25689.

16 Vid. PARDO, 2005. POWELL, 2011. LEMUS, 2011.

17 Más detalles en ORTUÑO, 2005: 192-193. SANZ, 2012: 774-775. MUÑOZ SÁNCHEZ, 2012: cap. 4.

18 Antes habían viajado a Estados Unidos. Juan Carlos I era el primer jefe del estado español en visita oficial a Francia desde hacía más de setenta años.

19 AMAE-F, Europe, Espagne, 1971-76, varios vols.

20 Telegrama del embajador Emmanuel de Margerie, Madrid, 28/10/1980. AMAE-F, Europe, Espagne, 1977-81, vol. 4365. 
ron otras instituciones encargadas de fomentar el acercamiento bilateral, como l'Office Franco-espagnole de Rapprochement d'Entreprises, patrocinada por las organizaciones patronales de ambos países; y el Instituto Universitario de Tecnología de Bayona, un centro de enseñanza bilingüe encargado, según su carta fundacional, de «proporcionar a los empresarios franceses un mayor conocimiento del mercado español, animándoles a cruzar los Pirineos [...] y enseñar a los empresarios españoles el funcionamiento del Mercado Común, facilitándoles las operaciones intracomunitarias» ${ }^{21}$. Desde finales de los años ochenta, se institucionalizaron, además, cumbres bilaterales anuales a nivel de jefes de estado y gobierno, con sus cohortes respectivas de ministros y exper$\operatorname{tos}^{22}$.

\section{LOS DESENCUENTROS POLÍTICOS: TERRORISMO VASCO Y ADHESIÓN ESPA- ÑLA A LA CEE}

Pese a los apoyos manifestados por Francia al inicio del proceso de transición, las tensiones no tardaron en llegar: la falta de entendimiento en la lucha contra ETA y la adhesión de España a la CEE marcaron unos años de relaciones complejas e inestables:

Deux problèmes majeurs pèsent sur nos relations bilaterales, entretiennant un climat de défiance, animosité et malentendus dont il est difficile de sortir [...] interfèrant même dans les questions de caractère technique: l'affaire basque et l'adhésion espagnole à la Communauté ${ }^{23}$.

El primer problema de fondo fue el terrorismo vasco. Muchos franceses, desconocedores de la evolución socio-económica primero y política después de la sociedad española, miraban a los miembros de ETA con simpatía (y hasta empatía), presentándoles como combatientes frente a la opresión franquista, aplaudiéndoles como defensores de la libertad del pueblo vasco, e incluso comparándoles con los resistentes franceses al nazismo ${ }^{24}$. Otros, más

21 «Relations franco-espagnoles», informe de Robert Hourcaillou, cónsul general de Francia en San Sebastián, al embajador de Francia en España, Madrid, 7/3/1975. AMAE-F, Europe, Espagne, 1971-76, vol. 446.

22 Al respecto, MESTRES, 2006: 154-157.

23 «Préparation de la mission en Espagne de M. Racul Delaye», nota del MAE-SDEM, París, 6/1/1980. AMAE-F, Europe, Espagne, 1977-81, vol. 4351.

24 Por ejemplo Gaston Defferre, antiguo resistente y ministro del Interior con Mitterrand. Ref. ACUÑA, 1986: 106. MORÁN BLANCO, 1997: 199. LEMUS, 6 (Madrid, 2005): 71. Los diarios de izquierda y centro-izquierda (L'Humanité, Libération, Le Monde) recogieron múltiples declaraciones en este sentido. PINILLA, 2013: 130-135. 
realistas, reconocían la gravedad de los delitos cometidos por los etarras, pero temían que en España se les privase de sus derechos fundamentales y se les aplicasen métodos dictatoriales incluso después de 1975. Por último, un porcentaje significativo tanto de dirigentes como de ciudadanos franceses de a pie manifestaba, simplemente, una actitud discreta o indiferente ante lo que consideraba un problema interno de España. El caso es que los activistas de ETA gozaron en Francia del estatuto de refugiado político, pudiendo utilizar los medios de comunicación franceses para reivindicar sus atentados y el territorio francés como campo de entrenamiento, centro financiero y base de repliegue tras sus crímenes, siempre que no transgrediesen las leyes nacionales ${ }^{25}$.

Las autoridades españolas solicitaron reiteradamente la extradición a España de los miembros de ETA refugiados en Francia, sobre todo tras el asesinato de Carrero Blanco en diciembre de 1973. Pero el gobierno francés rechazó las demandas una tras otra, justificándose en el carácter «político e interior» de los delitos y, en consecuencia, la imposibilidad de extradición de sus autores según la Convención Franco-española de Extradición de 1877, la Constitución Francesa de 1958 y el Derecho Internacional (en particular, la Convención de Ginebra de 1951 y la Resolución de Naciones Unidas de $1967)^{26}$. Para acallar las protestas, el gobierno francés prometió una mayor cooperación entre los Ministerios del Interior y la policía de ambos países ${ }^{27}$. Después realizó algunas concesiones más, a fin de «éviter une dégradation des relations franco-espagnoles qui pourrait porter atteinte aux intérêts français» ${ }^{28}$ : pidió oficialmente disculpas por las manifestaciones pro-ETA habidas en Francia, retiró algunos carnets de refugiado político, intensificó las operaciones de vigilancia en las regiones fronterizas, e impuso algunos arrestos domiciliarios en áreas alejadas de los Pirineos. Pero no fue suficiente. La actitud francesa, espoleada por la prensa española, había expandido actitudes francófobas en amplias capas de la sociedad española: los más diplomáticos hablaban de pasividad, tolerancia y apoyo soterrado a ETA; los más exaltados de vecinos crueles y cómplices de asesinos ${ }^{29}$.

25 Para más detalles, PIÑUEL, 1986. ACUÑA, 1986. MORÁN BLANCO, 1997. MANSVELT, 2005. CASANOVA, 2008. AVILÉS, 2010.

26 «Voyage de M. Schumann en Espagne», nota del MAE-SDEM, París, 22/8/1973. AMAE-F, Europe, Espagne, 1971-76, vol. 445.

27 «Réclamations espagnoles à propos de l'activité de certains réfugiés», nota del MAESDEM, París, 30/10/1974. AMAE-F, Europe, Espagne, 1971-76, vol. 446.

28 «De la visite du roi d'Espagne en France», informe del MAE-SDEM, París, 9/9/1976. AMAE-F, Europe, Espagne, 1976-80, vol. 4394.

29 Dossier de prensa española incluido en «Préparation de la mission en Espagne de M. Racul Delaye», nota del MAE-SDEM, París, 6/1/1980. AMAE-F, Europe, Espagne, 1977-81, vol. 4351. 
La documentación diplomática francesa revela que los gobiernos de Pompidou y Giscard d'Estaing se debatieron continuamente entre la necesidad de complacer a sus homólogos españoles, para obtener las contrapartidas económicas y militares deseadas, y la voluntad de mantener la tradición de Francia como tierra de asilo y derechos humanos, cuestión recogida en la legislación francesa y reivindicada con frecuencia por su opinión pública ${ }^{30}$. No obstante, el fiel de la balanza se inclinó progresivamente hacia la condena a ETA. ¿Por qué? Pesaron por supuesto las compensaciones económicas y militares prometidas por los españoles. También la presión ejercida por los empresarios franceses con negocios en territorio vasco, como las filiales de $\mathrm{Mi}$ chelin en San Sebastián y Vitoria, que exigieron mayores garantías de orden público para continuar operando en la zona ${ }^{31}$. Además, los responsables franceses temían el «contagio» a Francia no sólo del terrorismo sino también del movimiento autonómico, sobre todo tras el aumento de la actividad armada de Iparretarrak en el País Vasco francés ${ }^{32}$. Finalmente, la consolidación de la democracia en España acabó por deslegitimar cualquier intento de justificación de los atentados: ETA no tenía razón de ser en un país democrático. En la primera mitad de los años ochenta, con Mitterrand al frente del ejecutivo francés, se sentaron por fin las bases de la cooperación anti-terrorista en el triple frente policial, judicial e informativo, eliminándose la concesión del estatuto de refugiado político y acordándose, en septiembre de 1984, las primeras extradiciones.

El segundo contencioso serio que enfrentó a ambos países giró en torno a la adhesión de España a la CEE. El ingreso en esta institución había formado parte de la agenda de política exterior del gobierno español desde principios de los años sesenta, ligado a los procesos de desarrollo económico y rehabilitación internacional del régimen de Franco. No obstante, la ausencia de democracia no permitió ir más allá del Acuerdo Preferencial de 1970, basado en un calendario asimétrico de reducciones proteccionistas en beneficio de España y de los bienes industriales. La voluntad de ingresar como miembro de pleno derecho resurgió con fuerza en los primeros años de la transición. Entre enero y marzo de 1976, el ministro de Asuntos Exteriores José $\mathrm{M}^{\mathrm{a}}$ de Areilza visitó las capitales de los nueve países comunitarios ${ }^{33}$ para informar y convencer de las reformas democratizadoras en curso, esgrimiendo la adhesión

30 «Difficultés franco-espagnoles diverses», nota del MAE-SDEM, París, 20/6/1975. AMAE-F, Europe, Espagne, 1971-76, vol. 446.

31 Séance de l'Assamblée Nationale (résumé), 20/11/1972. AMAE-F, Europe, Espagne, 1971-76, vol. 404.

32 AGUILAR: 1986: 157. La historia de Iparraterrak en MORUZZI y BOULAERT, 1988. JACOB, 1994. BIDEGAIN, 2011.

33 Alemania, Francia, Italia, Bélgica, Luxemburgo, Países Bajos (1951), Reino Unido, Irlanda y Dinamarca (1973). 
como un factor legitimador sine qua non del proceso reformista ${ }^{34}$. Dos años más tarde, se creó el Ministerio para las Relaciones con las Comunidades Europeas, presidido sucesivamente por Leopoldo Calvo-Sotelo y Eduardo Punset, y encargado de capitanear el proceso de negociaciones ${ }^{35}$.

Antes y después de 1975, los dirigentes franceses comunicaron a los españoles su intención de apoyar firmemente a España en el camino hacia la CEE, por razones histórico-culturales, por la búsqueda de equilibrio entre los flancos centro-norte y sur de la Comunidad, y por el deseo de mitigar el predominio mundial de Estados Unidos. No negaron, sin embargo, las dificultades que implicaría la ampliación, tanto para los estados miembros como para algunos sectores y regiones francesas, y así se lo hicieron saber, en más de una ocasión, a las autoridades españolas, que calificarían esta actitud de «ambigua» ${ }^{36}$. A la hora de la verdad, el gobierno francés acabó por aplicar, en pro de intereses propios, un duro pragmatismo que retrasó la adhesión durante una década. ¿Cuáles fueron las objeciones francesas a la aventura europea de España?

En primer lugar, la fuerte competencia entre los productos agrarios españoles y franceses, especialmente los mediterráneos: frutas, legumbres, vino y aceite de oliva. Los agricultores franceses, sobre todo de los departamentos del Sur (Midi), temían que la liberalización económica asociada a la entrada en la CEE se tradujese en la afluencia masiva de alimentos españoles, que por sus ventajas comparativas (calidad similar-precio inferior) reemplazarían a los franceses dentro y fuera del espacio comunitario. De hecho, el desequilibrio a favor de España de los intercambios agroalimentarios franco-españoles se había mantenido constante desde 1945. Si la balanza comercial general presentaba saldos favorables a Francia era por el beneficio compensatorio de los intercambios industriales ${ }^{37}$. Las protestas de los agricultores del Midi se materializaron en la destrucción de camiones españoles a su paso por el territorio francés. Varios partidos políticos y asociaciones empresariales galas alimentaron el enfrentamiento al insistir en la miseria y conflictividad que en las regiones del Sur de Francia provocaría la invasión de productos agrarios españoles ${ }^{38}$. Estos argu-

34 «Entretiens avec le Comte de Motrico, ministre espagnol des Affaires Étrangères», Communication au Conseil des Ministres, París, 14/1/1976. AMAE-F, Europe, Espagne, 1971-76, vol. 446.

35 Para ampliar la información sobre el proceso de negociaciones España-CEE, consúltense: ALONSO, 1985. POWELL, 2003. CRESPO, 2004. TROUVÉ, 2008. CAVALLARO, 2009; 2013. MORENO, 2010. NÚÑEZ, 2013. También resultan de utilidad los libros de memorias de algunos de sus protagonistas, como AREILZA, 1977. CALVO-SOTELO, 1990; 1999. MORÁN LÓPEZ, 1990. BASSOLS, 1995. DENIAU, 1997.

36 Por ejemplo durante las visitas de altos cargos. Documentación en AMAE-E y AMAE-F.

37 Un estudio del comercio agroalimentario entre España y Francia en ÉTIENVRE y URQUIJO, 1989: 161-189.

38 Gaullistas, comunistas y la Fédération Nationale des Syndicats d'Exploitants Agricoles, fundamentalmente. BUSTURIA, 1994: 221-227. ACUÑA, 1986: 138-140. 
mentos se radicalizaron en vísperas de las elecciones francesas de 1978 (legislativas) y 1981 (presidenciales). Intimidado por la fuerza del voto campesino, el gabinete Giscard se comprometió a defender sus intereses, sobre todo en el contexto de las elecciones presidenciales ${ }^{39}$. Así, exigió a Bruselas, como paso previo al ingreso de España, una modificación de la Política Agraria Común (PAC) en el sentido demandado por los agricultores franceses, lo que se tradujo en la dilación sine die de las negociaciones España-CEE ${ }^{40}$. En la prensa española, las campañas anti-francesas, ya de por sí encendidas por el tema del terrorismo vasco, se volvieron especialmente duras a raíz de esta «pausa francesa»o $\left\langle\right.$ giscardazo» ${ }^{41}$.

De manera secundaria, preocupaban también en Francia cuestiones como el reparto de las aguas pesqueras, la pobreza relativa de algunas regiones españolas y un probable relanzamiento de la corriente migratoria en dirección sur-norte en aquel escenario de crisis económica y tensiones sociales. La competencia de los productos industriales españoles despertaba mucho menos recelo, a excepción, quizás, de la siderurgia, el textil, el calzado y la construcción naval en determinados momentos y coyunturas. En general, los empresarios franceses abogaban por acelerar el desarme aduanero hasta lograr una completa (aunque escalonada) liberalización del sector industrial. Pretendían incrementar la exportación de bienes franceses, dar salida a los productos fabricados en España por empresas dependientes financiera y tecnológicamente de Francia, y racionalizar la producción de las filiales españolas y francesas de un mismo grupo, en particular los constructores de automóviles Renault y Peugeot-Citroën y sus diversas industrias auxiliares ${ }^{42}$. Estos fueron grosso modo los argumentos esgrimidos ante Giscard por los miembros de la poderosa patronal francesa Conseil National du Patronat Français, cada vez

39 El discurso de Giscard ante las Cámaras Agrarias francesas el 5 de junio de 1980 dejó una larga estela en los medios.

40 Los franceses se plantearon la alternativa de endosar a la CEE los gastos derivados de la reconversión económica del Midi, aunque no llegaron a exponerla ante sus socios comunitarios. Vid. Intercambio de cartas entre Pierre Guidoni, embajador de Francia en España, y JeanClaude Paye, jefe del MAE-DAEF. AMAE-F, Affaires Économiques et Financières, Service de Coopération Économique, 1981-1983, vol. 1934.

41 El primero en utilizar el término «giscardazo» fue Ramón Pi en una crónica política publicada en La Vanguardia el 7 de junio de 1980. Ref. NÚÑEZ, 2013: 235. Vid. recortes de prensa en AMAE-F y AMAE-E y en el archivo hemerográfico del prof. Juan J. Linz: La Transición española en la prensa (1973-1987), http://www.march.es/ceacs/proyectos/linz [consultado en noviembre de 2015]. También MITTERRAND, 1986. CALVO-SOTELO, 1990; 1999. BASSOLS, 1995. TROUVÉ, 2008. NÚÑEZ, 2013.

${ }^{42}$ «Aide-mémoire sur l'intérêt d'une rationalisation de la production d'équipements automóviles au niveau franco-espagnol», informe del Ministerio francés de Industria e Investigación, Direction Générale de l'Industrie, París, 6/6/1978. AMAE-F, Europe, Espagne, 1977-81, vol. 446, 4379. 
más molestos por la «competencia desleal normalizada en el Acuerdo de $1970 »{ }^{43}$.

Entre las reticencias a la entrada de España en la CEE, cabe mencionar, finalmente, el escepticismo de algunos representantes del gobierno francés ante la desaparición de la herencia institucional franquista y la viabilidad de la joven democracia española, al menos hasta el fallido golpe de estado de 1981. Era una opinión compartida por los líderes de otros estados comunitarios, sobre todo holandeses y escandinavos, que dudaban de la capacidad española para implantar un sistema pluralista sólido y estable, dadas las malas previsiones económicas y la «falta de apego a la democracia» del pueblo español, acostumbrado a dar bandazos entre el caos y el orden, la anarquía y el absolutismo, la extrema derecha y la extrema izquierda ${ }^{44}$.

En términos generales, durante todo el proceso negociador la estrategia de la parte francesa estribó en ganar tiempo para conseguir imponer sus condiciones, desde el convencimiento de que, en el fondo, los Diez ${ }^{45}$ reconocían - cuando no compartían - la importancia de las dificultades invocadas por Francia, y agradecían incluso que Francia las expresase claramente para evitar tener que hacerlo ellos mismos:

Il n'est pas question de retarder systématiquement l'adhésion de l'Espagne, mais l'intérêt de la France est de disposer du temps nécessaire si elle veut imposser son point de vue $[\ldots]$ nos objectifs intéressent également nos partenaires ou certaines d'entre eux, même si la France est souvent isolée à Bruxelles quand elle en assure la défense ${ }^{46}$.

Giscard no fue el único líder, aunque sí el más visible, en plantear la necesidad de supeditar la ampliación de la CEE a la solución previa de sus problemas internos, en particular en los ámbitos agrícola y presupuestario. La necesidad de adaptar y modernizar la PAC llevaba tiempo en la agenda comunitaria, como reconoció el presidente del parlamento europeo, el italiano Emilio Colombo, en su visita a España en 1977: «La reestructuración de la agricultura es una necesidad a la que las perspectivas de la adhesión no hacen

43 «Visite à Madrid d'une délégation du CNPF», telegrama del embajador Jean-François Deniau, Madrid, 11/3/1977. AMAE-F, Europe, Espagne, 1977-81, vol. 4379. Despacho $n^{\circ} 778$ del embajador Miguel Solano, París 12/12/1978. AMAE-E, R-14585/4.

44 «Réunion consulaire des 13 et 14 mai 1980», informe de Margerie al MAE, Madrid, 3/6/1980. AMAE-F, Europe, Espagne, 1977-81, vol. 4351. La adhesión de España en el debate político francés en NÚÑNEZ, 2013: 173-198.

45 Grecia se había incorporado en 1981.

46 «Adhésion d'Espagne aux Communautés Européennes», informe del MAE-DAEF, París, 29/11/1983. AMAE-F, Affaires Économiques et Financières, Service de Coopération Économique, 1981-1983, vol. 1934. 
más que dar un carácter de mayor actualidad $[\ldots]\rangle^{47}$. Otros dirigentes europeos, como el canciller alemán Helmut Schmidt, admitirían también la urgencia de corregir los desequilibrios presupuestarios de la Hacienda europea antes de proceder a nuevas ampliaciones ${ }^{48}$. Desde el Ministerio español de Relaciones con la CEE, se criticó asimismo que se identificase a Francia como el principal - y casi único- obstáculo a la adhesión de España ${ }^{49}$. Al fin y al cabo, como han destacado algunos autores, el tema de las reforma internas, es decir la necesidad de un approfondissement previo al élargissement, hubiese condicionado las negociaciones España-CEE con o sin intervención de Giscard ${ }^{50}$.

En los primeros años ochenta, con las reformas agrícolas y presupuestarias en marcha, los socialistas al frente de los gobiernos francés y español, y la intermediación ejercida por el canciller alemán Helmut Kohl, Francia otorgó por fin su apoyo (sin préalables) al ingreso de España en la CEE. El 12 de junio de 1985 se firmó el Tratado de Adhesión, que entraría en vigor el 1 de enero del año siguiente ${ }^{51}$. La entrada en la CEE aceleró la difusión al conjunto de la sociedad francesa de la imagen de una España democrática, próspera y dinámica, imagen que posteriormente ratificarían los acontecimientos de 1992.

\section{LA CONTINUIDAD Y PROFUNDIZACIÓN DE LOS VÍNCULOS ECONÓMICOS}

Los desencuentros políticos apenas influyeron en las relaciones económicas bilaterales, que no notaron las disputas en torno a ETA o la CEE y mantuvieron el ritmo de crecimiento iniciado años atrás ${ }^{52}$. Es más, el interés y los esfuerzos de los empresarios franceses hacia el mercado español se acrecentaron ante el aumento relativo de las posiciones españolas (comercio) y extranjeras (inversión), y ante las perspectivas de liberalización derivadas del ingreso en la CEE: «[Il faut] être prêt, présent et connu le jour où le marché s'ouvrira définitivement» ${ }^{53}$.

47 «CEE. Relaciones con España. Visita del presidente Emilio Colombo (1977)». AMAEE, R-28296/5.

48 Boletín de las Comunidades Europeas, 1-1982, punto 1.2.2.

49 «Position du Gouvernement français concernant l'élargissement de la CEE», París, 11/6/1980. AMAE-E, R-17896/1.

50 ALONSO, 1985: 140-141. Más detalles en NÚÑEZ, 2013

51 La evolución de las negociaciones España-Francia-CEE durante la primera mitad de los años ochenta se examina en MORÁN LÓPEZ, 1990. TROUVÉ, 2008, 101/102 (París, 2011). NÚÑEZ, 2013.

52 SÁNCHEZ, 2006.

53 Informe del consejero comercial de la embajada de Francia en España con ocasión de la visita a la feria «Alimentaria» (Barcelona, 9-14/3/1980). AMAE-F, Europe, Espagne, 197781, vol. 4376. La cursiva es nuestra. 
¿Cómo evolucionaron las relaciones comerciales? Según las estadísticas del Ministerio español de Comercio, entre 1970 y 1985 el volumen y el valor de las importaciones españolas procedentes de Francia se multiplicaron, respectivamente, por 2,8 y 14,2. Para las exportaciones españolas con destino a Francia los multiplicadores fueron 3,2 y $36,8^{54}$. Desde 1977 la balanza comercial bilateral, que había sido tradicionalmente favorable a Francia, registró un saldo positivo a favor de España (gráfico 1). Varios factores explican esta inflexión. Primeramente, el incremento relativo de las ventas españolas de productos manufacturados, efecto combinado del Tratado Preferencial de 1970, las devaluaciones de la peseta de 1976 y 1977, el aumento de la producción con destino a mercados exteriores de las filiales españolas de multinacionales francesas, y la expansión de créditos, subvenciones y otras ayudas a la exportación. En segundo lugar, el estancamiento de las ventas francesas a España, por mor de la competencia de otras potencias extranjeras, la preferencia otorgada a la industria nacional y la caída de la demanda interna en los años de crisis. Habría que mencionar, por último, la no inclusión del armamento francés, fundamental en el comercio franco-español durante esta etapa, en los registros oficiales de ambos países.

GRÁFICO 1. Evolución del comercio español con Francia, 1970-1986 (en millones de pesetas de 1970)

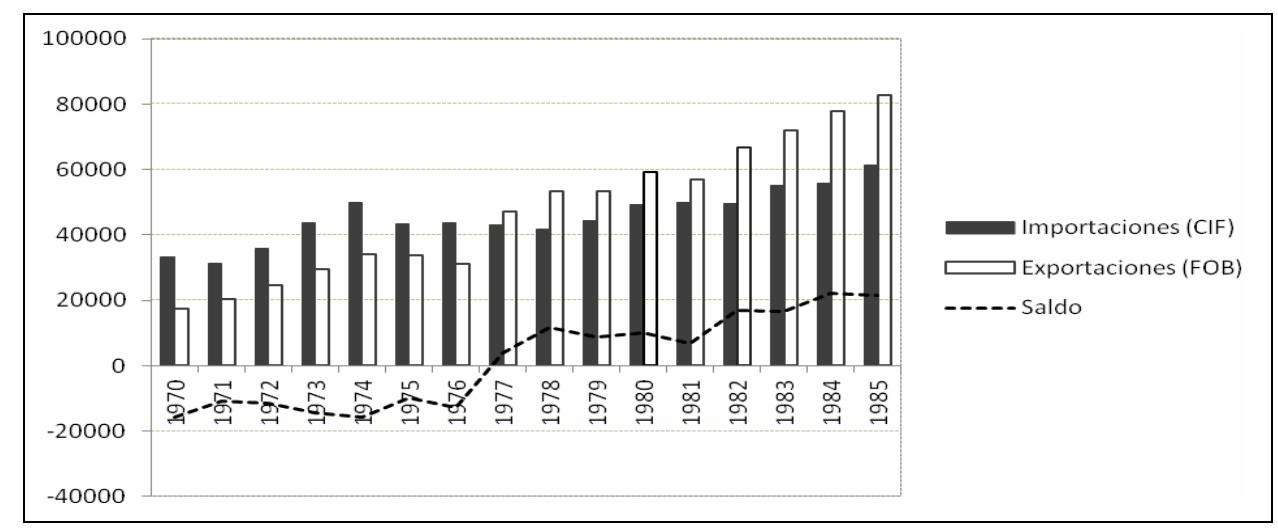

Fuente: Estadísticas del Comercio Exterior de España, Ministerio de Comercio, 1970-1986 y Carreras y Tafunell (2005) para IPC-deflactor

Según los datos disponibles, Francia se mantuvo entre los cuatro primeros puestos como cliente y proveedor de España, alternando posiciones con Esta-

54 BUSTURIA, 1994: 218-220. 
dos Unidos, Alemania y, a mayor distancia, el Reino Unido (gráficos 2 y 3). Como cliente, Francia absorbió entre 1970 y 1986 una media del 30\% de las ventas españolas a la CEE y el $14 \%$ del total mundial de la exportación española. Como proveedor, Francia suministró el $27 \%$ de las compras españolas a la CEE y el $9 \%$ del total de la importación mundial española ${ }^{55}$. En el comercio exterior francés, España mantuvo un peso relativo más reducido, tanto como cliente como proveedor ${ }^{56}$. Como puede observarse en los gráficos 2 y 3 , Estados Unidos perdió progresivamente importancia en el comercio exterior español en beneficio de los grandes países europeos.

GRÁFICO 2. Evolución de las importaciones españolas, 1970-1986. (porcentajes)

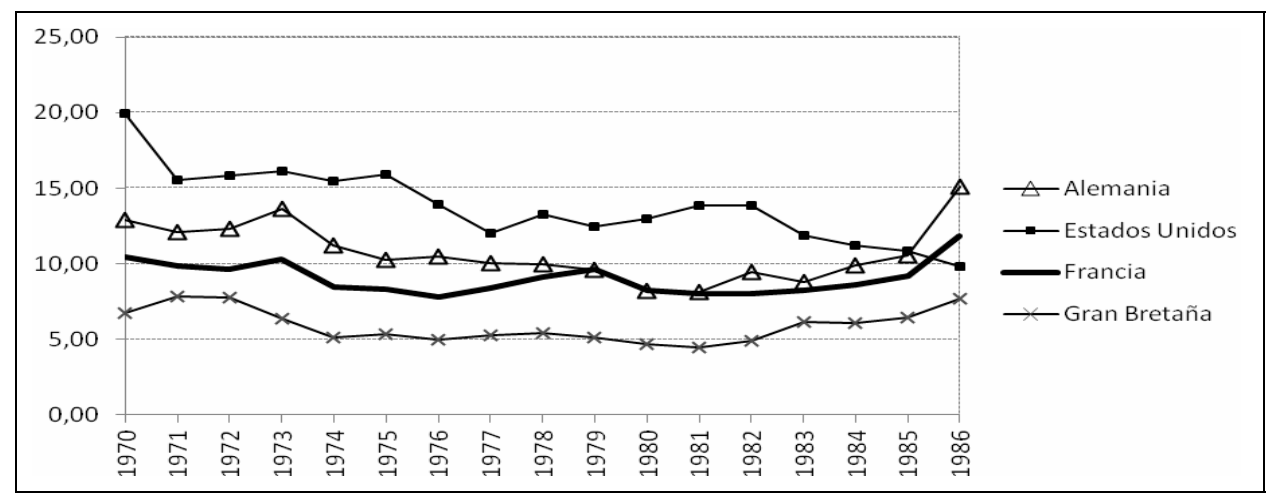

Fuente: Estadísticas del Comercio Exterior de España, Ministerio de Comercio, 1970-1987

Entre las ventas francesas a España, destacaron los bienes de equipo y consumo destinados a la industria y los servicios (en concreto, automóviles y sus piezas de recambio, maquinaria eléctrica y electrónica, productos químicos y siderúrgicos, y elementos relacionados con la informática). Por otro lado, encabezaron el ranking de las ventas españolas a Francia los automóviles de turismo fabricados por las filiales españolas de empresas francesas (con FASA-Renault y Citroën Hispania a la cabeza), seguidos por las piezas y recambios elaborados por esas mismas filiales y sus licenciatarias ${ }^{57}$. Los productos agroalimentarios

55 Estadísticas del Comercio Exterior de España, Ministerio de Comercio, 1970-1986.

56 «Espagne. Relations économiques bilaterales», nota del MAE-DAEF, París, 22/10/1976. AMAE-F, Europe, Espagne, 1977-81, vol. 4376.

57 Los productos del automóvil cubrieron por sí solos más de un tercio del total de la exportación española a Francia: el 37\% en 1982. Estadísticas del Comercio Exterior de España (1983), capítulo 87 del Arancel. 
disminuyeron progresivamente su peso en el conjunto de las importaciones españolas procedentes de Francia (del 10,5\% en 1970 al 5\% en 1986) y, sobre todo, en el conjunto de las exportaciones españolas con destino a Francia (del $43,7 \%$ al $15 \%$ en esos mismos años) ${ }^{58}$. La reducción de las ventas de alimentos y materias primas en beneficio de las de productos industriales (de mayor valor añadido) se había convertido en una tendencia general del comercio exterior español desde el desarrollo industrial de los años sesenta.

GRÁFICO 3. Evolución de las exportaciones españolas, 1970-1986. (porcentajes)

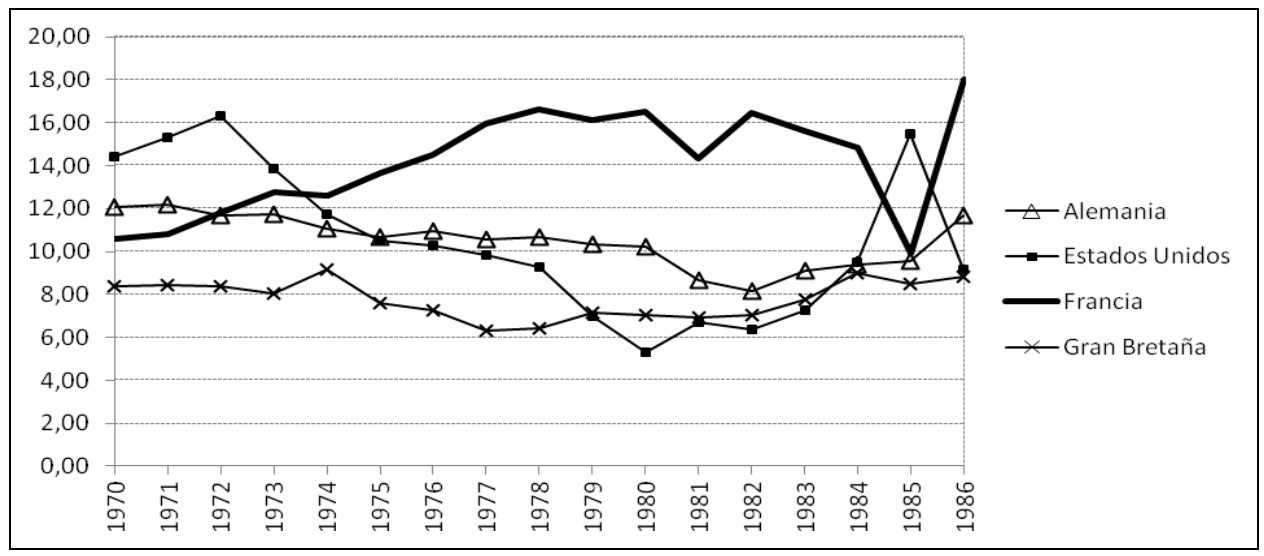

Fuente: Estadísticas del Comercio Exterior de España, Ministerio de Comercio, 1970-1987

Las tres partidas compensatorias tradicionales de la balanza española de pagos (turismo, emigración, inversión) conservaban aún un papel relevante en las relaciones franco-españolas, si bien los capítulos «emigración» y «turismo» habían perdido importancia respecto a la década dorada. En efecto, Francia continuó liderando las entradas de turistas extranjeros, con más de 10 millones de visitantes anuales, pero redujo en más de 10 puntos sus porcentajes de participación en el total: del $36 \%$ al $25 \%$ aproximadamente. El menor número de turistas (y gastos) españoles en Francia determinó un saldo medio anual de unos 2.500 millones de francos a favor de España en la balanza bilateral de pagos ${ }^{59}$. Con la crisis económica, la emigración permanente cambió de signo, interrumpiéndose las salidas e incrementándose los retornos: los

58 Estadísticas del Comercio Exterior de España, Ministerio de Comercio, 1970-1986.

59 Balance des paiements entre la France et l'extérieur: Espagne, Banque de France, 1970-1986. 
emigrantes españoles en Francia pasaron de 618.000 en 1973 a 570.000 en 1975 y a 445.000 en 1979, cifras que seguirían bajando en los años siguientes $^{60}$. Los trabajadores temporales (cerca de 100.000 al año) continuaban cubriendo en los años setenta el $90 \%$ de las necesidades francesas, sobre todo en actividades relacionadas con la vendimia. Por su parte, la colonia francesa en España, integrada por unas 50.000 personas (15.000 con doble nacionalidad), en su mayoría residentes en Madrid y Barcelona y con altos niveles educativo y profesional, constituía a la muerte de Franco el grupo de población extranjera más importante después del portugués ${ }^{61}$.

¿Qué ocurrió con la inversión francesa en España? El capital francés, por lo general asociado a tecnología y bienes de equipo de origen también francés, continuó privilegiando el mercado español como destino de inversión preferente, lo mismo que los capitales norteamericanos, alemanes, suizos y británicos, cuyo protagonismo relativo varió según los años. Entre los atractivos que brindaba el mercado español, destacaban la proximidad geográfica, el conocimiento y experiencia acumulados, la abundancia y bajo coste de la mano de obra, el potencial de crecimiento de la demanda interna, las necesidades de industrialización pendientes, y la posibilidad de utilizar este mercado como trampolín para la exportación a América Latina, el norte de África y Oriente Próximo, valiéndose del ascendiente histórico y/o cultural de España sobre estas regiones ${ }^{62}$.

Como en décadas anteriores, a la hora de fundar o expandir negocios en España, las multinacionales francesas solían realizar estudios de mercado (directamente o a través de consultoras), aprovechar la existencia de un tejido comercial previo, y buscar socios locales que facilitasen el acceso a los permisos oficiales, el acercamiento a los modos autóctonos y la creación de un clima de opinión favorable a los negocios franceses. Los banqueros José María Aguirre Gonzalo, Juan Lladó y los hermanos Fierro, representantes, respectivamente, del Banco Español de Crédito, el Banco Urquijo y el Banco Ibérico, figuran entre los socios más destacados de los franceses. También grandes empresarios como el catalán Pere Duran i Farell, y directivos de las Cámaras de Comercio e Industria españolas o franco-españolas, como Juan Abelló Pascual, presidente de la Cámara de Madrid, y Andreu Ribera, presidente de la de Barcelona.

60 Informe del consejero comercial, Madrid, 19/4/1977. AMAE-F, Europe, Espagne, 1977-81, vol. 4351.

61 «L'Espagne en mutation», misión de inspección en España de la Embajada de Francia en Madrid, junio 1976, Madrid, 24/8/1976. AMAE-F, Europe, Espagne, 1977-81, vol. 4351.

62 En general, se trata de factores de localización idénticos a los de la inversión francesa en España en la década anterior, y muy similares a los del conjunto de la inversión extranjera en España en la segunda mitad del siglo XX. Sobre la inversión foránea, especialmente francesa y norteamericana, en España vid. SÁNCHEZ, 2006. TASCÓN, 2008. PUIG y CASTRO, 2009. PUIG, ÁlVARO y CASTRO, 2009. CASTRO, 2010. ÁlVARO, 2012. Un análisis teórico de los factores de localización en BAJO, 1991. MUÑOZ GUARASA, 1999. 
Durante los años setenta y primeros ochenta, el origen geográfico de la inversión extranjera en España fue concentrándose progresivamente en la CEE, si bien Estados Unidos conservó un lugar prioritario. En torno al 10-15\% del total de la inversión exterior en España correspondió a Francia, que ocupó uno de los cuatro primeros puestos a nivel mundial, detrás de Estados Unidos, y en posiciones próximas a Alemania, Gran Bretaña y Suiza ${ }^{63}$ (gráfico 4).

A mediados de los años ochenta, prácticamente todos los grandes grupos empresariales franceses tenían representación en España. El Ministerio francés de Hacienda contabilizó más de 1.000 firmas, en su mayoría emplazadas en las regiones de Madrid (43\%) y Cataluña (27\%), y establecidas antes de 1975 (c. 75\%) ${ }^{64}$. Por sectores, destacaban el automóvil y sus piezas de recambio (Renault, Peugeot-Citroën, Michelin, Valeo, Ducellier), la química y petroquímica, (Saint Gobain, Péchiney-Ugine Kuhlmann, Air Liquide, RhônePoulenc, Institut Français du Petróle, Société Nationale des Pétroles d'Aquitaine, Coparex), la gran distribución (Carrefour, Promodès, Auchan), el material eléctrico, electrónico y electromecánico (Alsthom, Thomson-CSF, Cie Générale d'Électricité, Cie. Générale des Lampes, Stein \& Roubaix, Moulinex, Videocolor, CII-Honeywell-Bull), la industria alimentaria (Unigrain, Lesieur-Cotelle, Danone, Font Vella), la banca (Crédit Lyonnais, Banque Nationale de Paris, Société Générale) y los seguros (L’Union, Le Phénix, L'Abeille). Además, el capital francés mantenía una posición relevante en el sector de la minería, con empresas centenarias como Peñarroya o Piritas de Huelva, y otras más recientes como Recherches Géologiques et Minières. Sobresalían, por último, un conjunto de sociedades de ingeniería, sin implantación industrial ni comercial, que prestaron asistencia técnica a numerosas firmas españolas y proyectos de desarrollo emprendidos a este lado de los Pirineos: las Sociétés Françaises d'Études (SOFRES) ${ }^{65}$.

La crisis del petróleo no afectó en exceso a las grandes filiales industriales francesas en España. Enseguida remontaron el estancamiento o enjugaron las pérdidas mediante la modernización (robotización e informatización) de sus instalaciones y el remplazo de los programas de expansión geográfica y sectorial aprobados en años anteriores por el fomento de las regiones y productos

63 Como venía sucediendo desde el final de la II Guerra Mundial, el peso de Suiza está sobrevalorado, puesto que muchas compañías europeas y norteamericanas realizaron sus operaciones financieras en España a través de filiales domiciliadas por razones fiscales en aquel país, atribuyéndosele el origen nacional de la inversión. A título ilustrativo, las francesas Renault y Saint Gobain invirtieron en España a través de sus filiales suizas Renault Holding y Saint Gobain International.

64 «L'implantation française en Espagne», informe del jefe del Servicio de Expansión Económica de la Embajada de Francia en España, Madrid, 8/4/1987. CAEF, B55301.

65 Fueron especialmente relevantes la asistencia de Sofrerail al Plan de Modernización de RENFE y de Sofremines a la reestructuración de la industria del carbón en Asturias. Vid. CASTRO y SÁNCHEZ, 24 (Oxford, 2015). 
para los que disponían de mayor ventaja comparativa. Incluso algunas firmas como Péchiney-Ugine Kuhlmann, Rhône-Poulenc o Renault construyeron nuevas fábricas en plena crisis. En los planes franceses de inversión industrial en España, las expectativas de beneficio a medio y largo plazo primaron sobre cualquier altercado político o contrariedad económica, por lo general concebidos como meramente circunstanciales.

GRÁfICO 4. Porcentajes de la inversión directa de Francia, Alemania y EEUU en España, 1970-1986

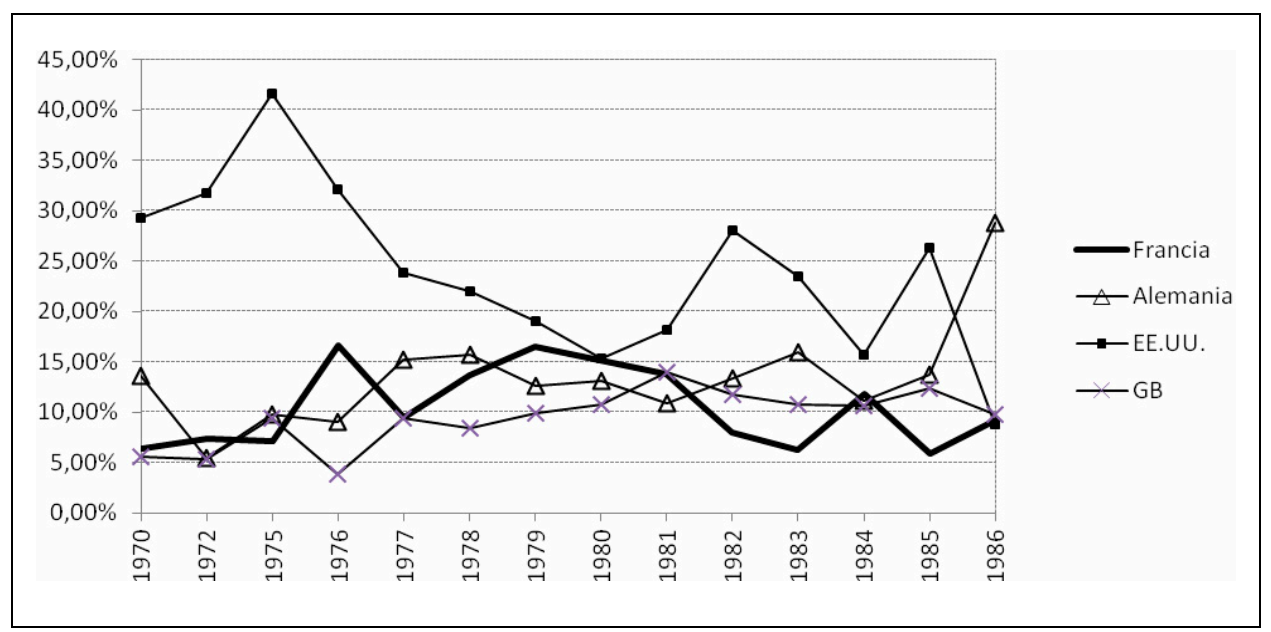

Fuente: Balance des paiements entre la France et l'extérieur: Espagne, Banque de France, Direction Générale des Services Étrangers, 1970-1987 y revista Economía Industrial, varios números

Al compás de la terciarización de ambas economías, el capital francés se fue trasladando al suministro de servicios, sobre todo los ligados a la banca y la gran distribución. Los bancos franceses ampliaron su presencia en España tras la liberalización bancaria de finales de los setenta y principios de los ochenta, especializándose en la financiación al sector público y a grandes empresas estatales como RENFE y las del Instituto Nacional de Industria (INI). No obstante, después de unos años de crecimiento, acabaron relegados a una posición marginal ante el empuje de las entidades bancarias nacionales. Algunos, como el Crédit Lyonnais, se vieron obligados a dar un adiós definitivo; otros, como la Société Générale y Paribas, focalizaron su actividad en la gestión de unos pocos grandes patrimonios y en la concesión de créditos al consumo ${ }^{66}$. Mayor

${ }^{66}$ La trayectoria de la banca francesa en España se estudia en CASTRO, 2010a: 221-236; 2012. 
éxito reportó el sector de la gran distribución. Las primeras cadenas de hipermercados (que a diferencia de los supermercados establecidos en décadas anteriore ${ }^{67}$ integraban productos alimentarios y no-alimentarios) llegaron a España a principios de los setenta de la mano del grupo francés Carrefour ${ }^{68}$. Entre 1973 y 1977 Carrefour inauguró en España un total 13 establecimientos, en su mayoría creados bajo la marca Pryca (acrónimo de «precio y calidad») y ubicados en la costa mediterránea (destino preferido de los turistas franceses en España). Durante los años siguientes, se multiplicaron tanto el número como los lugares de emplazamiento de los centros Carrefour, sobre todo tras el ingreso de España en la CEE: de 3,3 aperturas por año en 19731986 a 9,1 en 1986-1996 ${ }^{69}$. Muchos de aquellos productos agrarios franceses cuya ruina tanto temió Giscard d'Estaing ante la competencia de los españoles coparon las estanterías de estos nuevos establecimientos. Con el tiempo, Carrefour introdujo en España las innovaciones comerciales propias del grupo, como la política de descuentos y las «marcas blancas». También potenció la integración en el mercado local, mediante la firma de acuerdos con productores y distribuidores autoctonos y el aumento de la proporción de productos frescos, especialmente en el ramo de la pescadería ${ }^{70}$. A diferencia de los ban$\cos$, las grandes superficies comerciales francesas pueblan hoy el paisaje de las ciudades españolas.

Dado el diferencial en el grado de desarrollo de ambos países, la inversión española en Francia quedó muy por detrás de la inversión francesa en España. Apenas 100 empresas españolas, en su mayoría familiares, de tamaño medio, y originarias de Cataluña y el País Vasco, se establecieron en París (ingeniería, banca, moda) y en las regiones fronterizas del Sur (textil, automóvil, química, agroalimentario), aprovechando la contigüidad geográfica, la red de infraestructuras, el marco legal favorable, la mano de obra cualificada y otras externalidades propias de los distritos en los que se implantaron ${ }^{71}$. En 1979, Francia acogía el 6,7\% del total de la inversión española en el extranjero, situándose en quinta posición detrás de México (20,5\%), Estados Unidos $(15 \%)$, Argentina $(7,8 \%)$ y Venezuela $(7,4 \%)^{72}$. En el desembarco de las mul-

67 Algunos importados directamente de Estados Unidos y otros indirectamente previo paso por Europa o Latinoamérica. Vid. GARCÍA RUIZ, 49/3 (Cambridge, 2007). MAIXÉALTÉS, 41/3 (Barcelona, 2009).

68 La firma Carrefour, fundada en 1959, estableció su primer hipermercado en Sainte Geneviève des Bois, a las afueras de París, en 1963. España constituyó su segundo país de internacionalización, después de Bélgica. CASTRO: 2010b: 105.

${ }^{69}$ CASTRO: 2010b: 114 y 117. Más información en CASTRO, 2010a; 44/3 (Barcelona, 2010b).

70 LHERMIE, 2003: 54.

71 CASTRO, 849 (Madrid, 2009): 51.

72 «L'essor des investissements espagnols à l'étranger», informe del jefe del Servicio de Expansión Económica de la Embajada de Francia en España, Madrid, 5/3/1973. CAEF, B55301. 
tinacionales españolas al norte de los Pirineos, cabe destacar la labor de dos organismos creados a mediados de los años sesenta: la Délégation à l'Aménagement du Territoire et à l'Action Régionale (DATAR), encargada de corregir los desequilibrios regionales del territorio francés, y la Conférence Permanente de Chambres de Commerce, d'Industrie et de Navigation du SudOuest de la France et du Nord de l'Espagne (COPEF), que integraba las Cámaras de Comercio e Industria de las regiones más próximas a los Pirineos (las más pobres de Francia y más ricas de España) y tenía como primera misión potenciar las relaciones económicas entre ellas ${ }^{73}$. En todo caso, la inversión española en Francia mantuvo durante esta etapa una posición marginal, ya que apenas alcanzó el 1\% del total de la inversión extranjera en el país ${ }^{74}$.

\section{LAS RESPUESTAS DEL GOBIERNO FRANCÉS AL DECLIVE DEL COMERCIO Y LA INVERSIÓN EN ESPAÑA}

El déficit comercial de 1977, superior al registrado entre España y los demás países comunitarios, despertó enseguida la preocupación de los responsables y productores franceses:

L'évolution rapide des échanges franco-espagnols en faveur de l'Espagne suscite chez nos industriels et nos producteurs agricoles une très vive inquietude et des critiques acerbes $[\ldots]$ nous ne cherchons pas à ériger en dogme l'équilibre absolu des échanges, mais $[\ldots]$ obtenir un peu plus d'égalité» ${ }^{75}$.

Los afectados denunciaron los desequilibrios del Tratado Preferencial ( $25 \%$ vs $5 \%$ de derechos aduaneros a la entrada de bienes en España y en la CEE) y exigieron la desaparición de otras prácticas proteccionistas e intervencionistas que obstaculizaban la exportación francesa a España (contingentes, licencias, impuestos, etc. $)^{76}$. Las autoridades francesas, al tiempo que trasladaron sus protestas a las españolas, intentaron acrecentar el interés del

73 «Francia-España. Conversaciones de hombres de negocios: reuniones y actividades de la COPEF». AMAE-E, R-7742/4 y R-9873/8.

74 «Rapport d'activité de l'Ambassade de France en Espagne, 1973». CAEF, B54204. Un estudio más detallado en CASTRO, 2009.

75 «Contentieux franco-espagnol dans le domaine comercial», informe del Ministerio francés de Economía, Direction des Relations Économiques Extériéures, París, 16/5/1978. AMAE-F, Europe, Espagne, 1977-81, vol. 4377.

76 Pese al Plan de Estabilización de 1959, el ingreso en los organismos económicos internacionales y otras medidas posteriores, la política comercial española mantuvo una importante dimensión proteccionista en forma de barreras arancelarias y regímenes discriminatorios. Prueba de ello es que a la entrada en la CEE la tasa de apertura exterior de la economía española era aún la más reducida de la Comunidad. CARRERAS y TAFUNELL, 2010: 652. 
empresariado galo por el mercado ibérico, a través de una acción combinada de información y encuentros. Para empezar, ampliaron los datos disponibles en Francia sobre la economía española, con más y mejores estadísticas, estudios de mercado y directorios de contactos; y para continuar, intensificaron la acción personal directa, a partir de la organización de estancias recíprocas, la participación en ferias y exposiciones, y la preparación de demostraciones «a domicilio» de los bienes franceses susceptibles de ser exportados (acompañados de manuales, preferiblemente en español, con todos sus detalles técnicos). Por último, desde el gobierno francés se sugirió fomentar la intervención de sindicatos profesionales y ofrecer a los importadores españoles contrapartidas en los ámbitos industrial y político ${ }^{77}$.

Mayor preocupación generaron las cifras de inversión. La confluencia entre lentitud administrativa, problemas financieros y férrea competencia extranjera había conducido al estancamiento de los grandes planes franceses de inversión industrial en España (con la excepción de la industria mili$\operatorname{tar})^{78}$. Se ponía de relieve que el Comité de Cooperación Industrial se encontraba en un «decepcionante punto muerto», pues muchos de los proyectos bilaterales planteados años atrás habían sido paralizados o adjudicados a empresas americanas o alemanas, v. g. la asociación de los centros siderúrgicos de Fos y Sagunto, la difusión del sistema SECAM de televisión en color, la compra de aviones Airbus por Iberia, la colaboración entre ENASA y Renault para la fabricación de vehículos industriales, y la participación de empresas francesas en la edificación de refinerías petrolíferas (ELF, CFP), en el suministro de equipos informáticos (Thomson-CSF, CIT-Alcatel) y en la puesta en funcionamiento de nuevos reactores nucleares (CEA, EDF) ${ }^{79}$. La atonía de la cooperación nuclear preocupaba especialmente al gobierno francés, que desde la construcción de la central franco-española de Vandellós ${ }^{80}$ y la

77 Informe del consejero comercial, Madrid, 19/4/1977. AMAE-F, Europe, Espagne, 1977-81, vol. 4351.

78 «Préparation de la mission en Espagne de M. Racul Delaye», nota del MAE-SDEM, París, 6/1/1980. AMAE-F, Europe, Espagne, 1977-81, vol. 4351.

79 «Necessité d'encourager le développement des investissements industriels français en Espagne», informe del consejero comercial, Madrid, 20/11/1970. CAEF, B55301. «Relations économiques et comerciales», informe del MAE-SDEM, París, 20/2/1980. AMAE-F, Europe, Espagne, 1977-81, vol. 4379.

${ }^{80}$ La central de Vandellós I, cuya construcción se inició en 1967, marcó el inició de la cooperación industrial franco-española en materia nuclear, tras más de una década de relaciones científico-técnicas. Para desbancar las ofertas nucleares de Estados Unidos, el gobierno francés, a través del CEA y EDF, consintió a su homólogo español prerrogativas excepcionales, de tipo financiero (préstamos a largo plazo y bajo interés), industrial (alto porcentaje de participación de la industria española) y político (control exclusivamente bilateral y atenuación de las cláusulas de utilización pacífica del material atómico). Dicho en pocas palabras, la central de Vandellós I respondió menos a objetivos económicos que político-militares, derivados de la voluntad española de escapar del monopolio nuclear norteamericano y potenciar el 
aprobación del programa nuclear español ${ }^{81}$ aspiraba a desempeñar un papel destacado en el sector.

Al inicio de la transición política española, franceses y españoles colaboraban en diversos proyectos bilaterales y multilaterales relacionados con la industria nuclear. Entre los bilaterales: la exploración y explotación de uranio natural en Níger (yacimiento de Akokan) por la Empresa Nacional del Uranio S.A. (ENUSA), perteneciente al INI, y su equivalente francesa la Compagnie Générale des Matières Nucléaires (COGEMA), del CEA. Entre los multilaterales: por un lado, la participación de ENUSA, al 11,1\%, en la sociedad europea de enriquecimiento de uranio EURODIF, que había puesto fin al suministro exclusivo de uranio enriquecido a España por parte de Estados Unidos; y por otro, la asociación de la Franco-Américaine de Constructions Atomiques (FRAMATOME) con diversos grupos españoles, destacando la empresa constructora Equipos Nucleares, la sociedad de ingeniería Empresarios Agrupados y el Banco Ibérico de los Fierro. No obstante, grandes proyectos como la construcción de las centrales de Vandellós II y III, Escatrón y Trillo habían escapado a la industria francesa, y otros como la fabricación de supergeneradores o de plantas para el tratamiento del combustible irradiado se encontraban en suspenso ante la revisión a la baja del programa nuclear español y la competencia de otros países, en particular, otra vez, Estados Unidos y la RFA.

La pérdida de posiciones no implicó pasividad o desaliento. Al contrario, aprovechando el cambio de régimen y los desequilibrios destapados por la crisis económica, el gobierno francés animó a sus industriales a relanzar la inversión en España. Era imprescindible emprender una acción ofensiva (que no agresiva), basada en la combinación de una serie de estrategias: a) prospección del mercado español, a fin de elaborar listas de sectores necesitados de capital y tecnología; b) exhibición de las capacidades industriales francesas en ferias, exposiciones, conferencias, reuniones de empresarios y otros eventos; y c) fundación de filiales de fabricación, preferiblemente en sectores de alta tecnología: telecomunicaciones, construcción aeronáutica y naval, informática, electrónica, automóvil, nuclear... ${ }^{82}$. La participación española en

desarrollo de una tecnología nuclear propia para fines civiles y militares. «Relations nucléaires avec l'Espagne», informe del Ministerio francés de Industria e Investigación, Direction Générale de l'Énergie, París, 17/8/1977. AMAE-F, Europe, Espagne, 1977-81, vol. 4367. La historia de la central de Vandellós I en SÁNCHEZ, 61 (Barcelona 2010a).

81 El Plan Energético Nacional de 1975 preveía una potencia nuclear de $23.000 \mathrm{MW}$ para 1985, esto es el 56\% de la producción total de electricidad. El Plan de 1978 redujo las previsiones a 10.500 MW. En 1979, España disponía de 3 centrales construidas (Zorita, Garoña y Vandellós I) y 7 en construcción (Almaraz I y II, Lemoniz I y II, Ascó I y II y Cofrentes), que en conjunto alcanzaban 7.600 MW. Más detalles en CUERDO, 15 (Barcelona, 1999) DE LA TORRE y RUBIO, 51 (Cambridge, 2015).

82 Nota de Jean-Pierre Dutet, consejero de comercio exterior, al Presidente de la República, París, 24/2/1978. AMAE-F, Europe, Espagne, 1977-81, vol. 4395. 
los procesos de producción se limitaría, en un primer momento, a la elaboración de piezas sueltas, recambios y elementos de bajo contenido tecnológico. Con el tiempo, y con asistencia francesa, los técnicos e ingenieros españoles estarían en condiciones de elaborar productos terminados ${ }^{83}$.

El gobierno francés animó tanto a inversores públicos como privados, intentando convencer a unos y otros de que la supervisión estatal evitaría la competencia franco-francesa y facilitaría la unión de fuerzas para enfrentar la competencia extranjera. Los grandes planes de inversión de los Champions Nationaux despertaban un interés particular, dada su capacidad para ofrecer a los españoles «compensaciones industriales y políticas»: "Comment faire pencher la balance en notre faveur en dépit de la concurrence européenne et américaine? [...] il faut les faire apprecier [aux Espagnols] à la fois les aspects économiques et politiques de nos projets $>{ }^{84}$. Las prestaciones políticas se resumían en dos: un apoyo más firme a la entrada en la CEE y la posibilidad de disminuir la dependencia respecto a Estados Unidos. Entre las compensaciones industriales destacaban tres: la firma de acuerdos de cofabricación, reservando a los españoles un alto porcentaje de participación en los procesos de producción; la concesión de facilidades financieras, sobre todo en forma de préstamos a largo plazo y bajo interés; y el apoyo a la exportación, a Francia y a terceros países, del material fabricado en España con licencias y asistencia técnica francesas. Los responsables galos consideraban que las decisiones de España influirían sobre las de países próximos geográfica y/o culturalmente a ella, como Portugal y los de América Latina, e incluso sobre las decisiones de países que, aunque lejanos, también buscaban escapar de la hegemonía norteamericana.

Como colofón, había que potenciar la cooperación educativa y científicotécnica con España (regulada en los Acuerdos de 1969 y 1974), sobre todo a partir de la firma de convenios entre universidades y centros de investigación de ambos países. Tres eran los ámbitos científicos de actuación prioritaria: Ciencias Naturales, Ingeniería y Energías; y cinco los técnicos: Administración del Estado, Economía, Desarrollo Rural, Urbanismo-Obras Públicas y Sanidad. Interesaba especialmente incrementar la influencia francesa en las enseñanzas superiores de Economía y Empresa, así como en los laboratorios de investigación de universidades y centros de $\mathrm{I}+\mathrm{D}$, hasta entonces dominados por los métodos y materiales de Estados Unidos; y captar más estudiantes de francés en todos los niveles del sistema educativo, a fin de frenar la ame-

83 Servicio de Expansión Económica de la Embajada de Francia en España, 21/12/1970. AN-CAC, 19800116/60.

84 Telegrama del embajador Robert Gillet, Madrid, 24/4/1975. AMAE-F, Europe, Espagne, 1977-81, vol. 417; «Relations franco-espagnoles en matière d'armements», nota del MAEDAEF, París, 9/2/1978. AMAE-F, Europe, Espagne, 1977-81, vol. 4365. 
naza monolingüística del inglés y lograr un mayor número de francófonos (y por tanto francófilos) en puestos clave de la política y la economía españolas. Las autoridades francesas prometieron impulsar la enseñanza del español y de la cultura española en Francia, no sólo para satisfacer las demandas de reciprocidad de sus homólogos españoles, sino además para aprovechar mejor las ocasiones de penetración económica en España ${ }^{85}$. A estos objetivos respondió el refuerzo de medidas como el intercambio de estudiantes, profesores y especialistas de la industria pública y privada, la realización de proyectos de investigación conjuntos, la donación de libros, revistas y materiales audiovisuales, la organización de enseñanzas bilingües, y el envío de misiones bilaterales a terceros países, empezando por los latinoamericanos. Actividades que el gobierno francés canalizó a través de las delegaciones competentes de los Ministerios de Economía y Finanzas y de Asuntos Exteriores, los Servicios de Cooperación Técnica y de Expansión Económica de la Embajada de Francia en España, y unas 60 instituciones estatales o paraestatales establecidas al sur de los Pirineos: liceos, escuelas, institutos, círculos de la Alianza Francesa y otras entidades docentes que en conjunto sumaban más de 26.000 alumnos a finales de los setenta ${ }^{86}$.

La cooperación industrial, educativa y científico-técnica debía resultar, en opinión francesa, lo más equilibrada posible, para ajustarse a los «cupos nacionales» exigidos por la legislación española, para lograr «clientes agradecidos» que actuarían cómo embajadores y propagandistas, y para no lastimar ese amor propio español que los franceses consideraban tan extremadamente sensible:

Les relations industrielles, techniques et culturelles avec l'Espagne son très importantes. Elles méritent d'être considerées sous l'angle d'une véritable coopération à double sens et non pas, comme avec bien d'autres pays, sur le plan d'une simple assistance de fournisseur à client $[\ldots]^{87}$.

El principio de aprovechar las renegociaciones de los Pactos de Madrid de $1953^{88}$ para proponer a los españoles proyectos que rivalizaran con los nor-

85 «Enseignement des langues Espagnole et Française», Telegrama de Margerie, Madrid 23/19/1979. AMAE-F, Europe, Espagne, 1977-81, vol. 4368.

86 «Politique de Culture et de Coopération», informe de Deniau al MAE, Madrid, 2/3/1977; $\mathrm{y}$ «Relations culturelles, scientifiques et techniques franco-espagnoles», notas del MAE-DRCST, París, 30/1/1978 y 15/11/1979. AMAE-F, Europe, Espagne, 1977-81, vol. 4368.

87 «Coopération industrielle avec l'Espagne», nota del Ministerio francés de Industria e Investigación, Direction Générale de l'Énergie, París, 26/11/1975. AMAE-F, Europe, Espagne, 1971-76, vol. 446.

88 Los Pactos de Madrid fueron renovados (con significativas modificaciones) en 1963, 1970, 1976, 1982, 1988 y 2002. Las obras de referencia son: VIÑAS, 2003. POWELL, 2011. 
teamericanos siguió estando muy presente en la acción francesa hacia España. En los años cincuenta y sesenta, Francia había conseguido quitar a Estados Unidos el liderazgo en algunos capítulos fundamentales de la economía española, como la política económica $^{89}$ o la industria del automóvil ${ }^{90}$. En los años setenta, consiguió imponerse, aunque de forma coyuntural, en el sector militar. Efectivamente, hasta 1970 prácticamente todo el material militar adquirido por España al extranjero era de origen norteamericano; desde ese año la parte americana disminuyó progresivamente en beneficio de la francesa, de forma que en 1979 Francia logró adelantar a Estados Unidos (gráfico 5). Ya en las primeras décadas del franquismo, Francia había incluido material de doble uso civil-militar en los acuerdos comerciales bilaterales, formado a altos mandos del Ejército español en sus más prestigiosas escuelas militares, y prestado asistencia técnica a compañías españolas relacionadas con la industria de la defensa, en su mayoría pertenecientes al INI. En 1970, tras muchos contactos y negociaciones, ambos gobiernos concluyeron una serie de acuerdos que intensificaron considerablemente la cooperación militar bilateral ${ }^{91}$, así como el aprovisionamiento al Ejército español de armamento con patente francesa pero de factura conjunta francoespañola: aviones Mirage, helicópteros Alouette, Gazelle y Puma, carros de combate $A M X$ y $A M L$, submarinos Agosta, misiles, radares, etc. ${ }^{92}$ A la larga, la

89 En materia de política económica, la planificación indicativa francesa fue la gran fuente de inspiración de los tecnócratas españoles, especialmente a la hora de elaborar los Planes de Desarrollo. Destacadas multinacionales francesas, como Renault, Michelin, Air Liquide, Saint Gobain o Péchiney-Ugine Kuhlmann, se acogieron a las subvenciones y ventajas físcales previstas en los Polos españoles de Desarrollo y Promoción, en gran medida por conocer de antemano estos programas. La planificación indicativa reforzó por tanto la cuota de mercado de Francia en España. Vid. SÁNCHEZ, 2006. DE LA TORRE y GARCÍA ZÚÑIGA, 2009. CASTRO y SÁNCHEZ, 24 (Oxford, 2015).

90 La industria francesa del automóvil llegó a España en los años cincuenta de la mano de Renault y Citroën, y consiguió, junto a Seat-Fiat, crear una situación de exceso de oferta que retrasó durante dos décadas el establecimiento de los gigantes americanos Ford y General Motors. Sobre el proceso de implantación y primeros años de actividad industrial de Renault en España, remitimos a SÁNCHEZ, 22/1 (Madrid, 2004). FERNÁNDEZ DE SEVILLA, 2013. Sobre Citroën Hispania, CARMONA y NADAL, 2005.

91 Por la vía de reuniones de ministros, estados mayores y otros altos cargos militares, instrucción y entrenamiento del personal español, maniobras conjuntas, viajes de estudios de alumnos y profesores de escuelas de guerra, utilización recíproca de instalaciones militares, facilidades de circulación y escalas en el territorio del otro país, intercambio de información, etc. Vid. especialmente el «Acuerdo de Cooperación Militar entre el Gobierno de la República Francesa y el Gobierno del Estado Español», firmado el 22 de junio de 1970, que actualizaba compromisos anteriores, los ratificaba a nivel gubernamental y los extendía a los tres cuerpos del Ejército, Marina, Tierra y Aire. Texto del acuerdo disponible en: http://www.diplomatie.gouv.fr/ traites/affichetraite.do?accord=TRA19700073 [consultado en marzo de 2014].

92 Los franceses desoyeron únicamente las peticiones españolas de fabricar submarinos y portahelicópteros de propulsión nuclear y de convertir los acuerdos técnicos en un verdadero Tratado de Defensa. Vid. SÁNCHEZ, 52/3 (Cambridge, 2010b); 50 (Cambridge, 2015). 
asistencia técnica y la co-fabricación permitieron a los socios y sociedades locales desarrollarse hasta el punto de convertirse en competidores en el mercado nacional, e incluso cruzar fronteras ${ }^{93}$.

GRÁFICO 5. Exportación de armas a España, 1950-1986

(millones de US\$ a precios constantes de 1999)

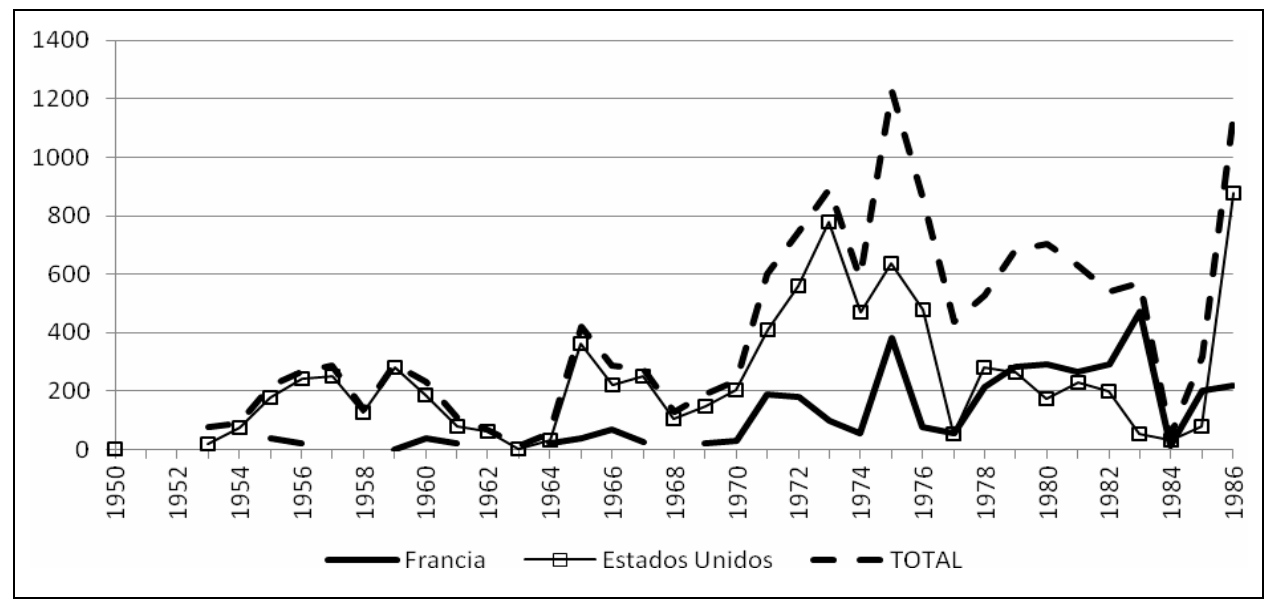

Fuente: AMAE-F y SIPRI, 1970-1986

\section{CONCLUSIÓN}

Tras la muerte de Franco, España y Francia esperaban mucho la una de la otra. España estaba convencida de que Francia sería su más firme aval en el camino hacia la CEE, y Francia aspiraba a apadrinar el proceso (moderado) de transición a la democracia para incrementar su influjo en España. Ahora bien, a la hora de la verdad, el gobierno francés tardó demasiado tiempo en reconocer la realidad del terrorismo de ETA y asumió las tesis de una parte minoritaria de los intereses económicos de Francia en España, creando una situación de gran tensión en las relaciones bilaterales. Al cabo, la influencia política alemana resultaría más decisiva que la francesa.

93 En 2010 las empresas Navantia, Indra Sistemas, Santa Bárbara y las plantas españolas de Airbus y Eurocopter exportaron materiales por valor de más de 1.100 millones de euros. En declaraciones al diario $A B C$, los dirigentes de estas entidades coincidían al señalar la buena salud de sus exportaciones, pese a la crisis, así como las grandes oportunidades de crecimiento previstas en Asia, Europa del Este, América Latina y África, sobre todo si se lograba «negociar de gobierno a gobierno». $A B C, 12 / 2 / 2012$. 
No obstante, como había ocurrido en épocas pasadas, las relaciones económicas entre España y Francia evolucionaron al margen de las relaciones político-diplomáticas, notando poco el cambio de régimen o las desavenencias sobre ETA y la CEE que se sucedieron en la etapa de transición. En efecto, las complicaciones económicas bilaterales no derivaron tanto de enfrentamientos políticos como de cuestiones de oferta y demanda. Salvo los agricultores del Midi, los medios económicos franceses vieron en España menos un molesto competidor que un atractivo mercado de inversión y exportación. Por ello, conservaron muchas de las estrategias económicas desplegadas durante la dictadura, como la promoción del contacto personal directo, la búsqueda de socios locales o la firma de acuerdos de co-fabricación. Estas estrategias, junto, por un lado, la voluntad — común a españoles y franceses-, de reducir la dependencia respecto a Estados Unidos, y por otro, la confianza francesa en el potencial de desarrollo de la economía española, resultaron decisivas a la hora de arrebatar a otras potencias extranjeras nichos de mercado en España, por ejemplo en la industria militar. Entonces, ¿por qué tanta insatisfacción por parte de las autoridades galas? Sin duda porque la competencia española y extranjera conquistaron más posiciones de las previstas, pero también porque los responsables franceses se empeñaron en potenciar la inversión industrial y el suministro de grandes equipos (en gran parte ligados a sociedades estatales) y relegaron la potencialidad del sector terciario (dominado por la empresa privada). Al final, fueron el sector servicios y la empresa privada los que, al menos en el caso de España, aportaron a Francia los mayores réditos tanto en términos de beneficio económico como de prestigio exterior.

Las cifras revelan importantes modificaciones en el patrón comercial e inversor de Francia en España durante el período analizado: la balanza comercial se volvió deficitaria y las inversiones industriales se estancaron ante el empuje del sector terciario y la competencia extranjera y española. Esta dinámica reflejaba un mayor equilibrio - $\mathrm{O}$ al menos un menor desequilibrio-, en las relaciones económicas bilaterales, lo que acabaría por extenderse al conjunto de las relaciones franco-españolas. A la postre, aunque Francia no tuviese el protagonismo que sus dirigentes esperaban, desde luego constituyó un interlocutor de primera fila en aquella España cuya faz cambiaba de forma acelerada. Y el gobierno galo, aunque no siempre acertase en sus estrategias de mayor recorrido, contribuyó ampliamente a la mejora y el equilibrio de los vínculos entre ambos países.

\section{Bibliografía}

Abadie, Frédéric y Corcelette, Jean-Pierre, Valéry Giscard d'Estaing, Paris, Nouveau Monde, 2009. 
Acuña, Ramón Luis, Como los dientes de una sierra: Francia-España, de 1975 a 1985, una década, Barcelona, Plaza y Janés, 1986.

Alonso, Antonio, España en el Mercado Común. Del Acuerdo del 70 a la Comunidad de Doce, Madrid, Espasa Calpe, 1985.

Álvaro, Adoración, La inversión directa estadounidense en España. Un estudio desde la perspectiva empresarial (c. 1900-1975), Madrid, Banco de España, 2012.

Angoustures, Aline, "L'opinion publique française et l'Espagne», Revue d'Histoire Moderne et Contemporaine, 37, París, 1990, 672-686.

Areilza, José María, Diario de un ministro de la monarquía, Barcelona, Planeta, 1977.

Aroca, Manuela, Internacionalismo en la historia reciente de la UGT, 1971-1986. Del tardofranquismo a la estabilización de la democracia, Madrid, Fundación Largo Caballero, 2011.

Avilés, Juan, El terrorismo en España. De ETA a Al Qaeda, Madrid, Arco, 2010.

Bajo, Óscar, «Determinantes macroeconómicos y sectoriales de la inversion extranjera directa en España», Información Comercial Española, 696-697, 1991, 53-74.

Banque de France, Direction Générale des Services Étrangers, Balance des paiements entre la France et l'extérieur: Espagne, Paris, Banque de France, varios años.

Barre, Raymond, L'expérience du pouvoir, Paris, Fayard, 2007.

Bassols, Raimundo, España en Europa. Historia de la adhesión a la CE, 1957-1985, Madrid, Política Exterior, 1995.

Bernecker, Walter, «España y Alemania en dos momentos decisivos de sus historias: la transición española y la reunificación alemana», Iberoamericana, 7/26, 2007, 153-165.

Berstein, Serge, Casanova, Jean-Claude y Sirinelli, Jean-François, Les années Giscard. La politique économique, 1974-1981, Paris, Armand Colin, 2009.

Bidegain, Eneko, Iparraterrak: historia de una organización política armada, Tafalla, Txalaparta, 2011.

Busturia, Daniel (ed.), Del reencuentro a la convergencia: Historia de las relaciones bilaterales hispano-francesas, Madrid, Fundación Diálogo, 1994.

Calvo-Sotelo, Leopoldo, Memoria viva de la Transición, Barcelona, Plaza y Janés, 1990.

Calvo-Sotelo, Leopoldo, Papeles de un cesante: la política desde la barrera, Barcelona, Galaxia Gutemberg, 1999.

Carmona, Xóan y Nadal, Jordi, El empeño industrial de Galicia, A Coruña, Fundación Pedro Barrié de la Maza, 2005.

Carreras, Albert y Tafunell, Xavier (coords.), Estadísticas históricas de España, siglos XIX-XX, Bilbao, Fundación BBVA, 2005.

Carreras, Albert y Tafunell, Xavier, Historia económica de la España contemporánea, Barcelona, Crítica, 2010.

Carrillo, Santiago, Memoria de la Transición, Barcelona, Grijalbo, 1983.

Casanova, Iker, ETA, 1958-2008. Medio siglo de Historia, Tafalla, Txalaparta, 2008. 
Castro, Rafael y Sánchez, Esther, «How Does Knowledge cross borders? The SOFRE group in the Spain of the Planning, 1959- 1976», Industrial and Corporate Change, 24, Oxford 2015; 1247-1283.

Castro, Rafael, «Experiencias previas a la gran internacionalización de la empresa española: el mercado francés y las instituciones, 1949-1980», Información Comercial Española, 849, Madrid 2009, 39-53.

Castro, Rafael, «'Máquinas de vender'. Una historia de la gran distribución francesa en España desde los años sesenta», Revista de Historia Industrial, 44/3, Barcelona 2010b, 97-137.

Castro, Rafael, Génesis y transformación de un modelo de inversión internacional: el capital francés en la España del siglo XX, Tesis Doctoral, Universidad Complutense de Madrid, 2010a.

Castro, Rafael, La banca francesa en la España del siglo XX, Madrid, Banco de España, 2012.

Catalan, Jordi, «Del 'milagro' a la crisis: la herencia económica del franquismo», en Etxezarreta, M. (coord.), La reestructuración del capitalismo en España, 19701990, Barcelona, FUHEM-Icaria, 1991; 95-130.

Cavallaro, Maria Elena, «La Francia di Giscard d'Estaing da madrina ad ostacolo dell'integrazione della Spagna in Europa», en Cavallaro, M. E. y Levi, G. (eds.), Italia e Spagna nel processo di integrazione europea (1950-1992), Soveria Mannelli, Rubbettino 2013, 99-121.

Cavallaro, María Elena, Los orígenes de la integración de España en Europa: desde el franquismo hasta los años de la transición, Madrid, Sílex, 2009.

Chirac, Jacques, Chaque pas doit être un but. Memoires I, Paris, NiL, 2009.

Crespo, Julio, España en Europa, 1945-2000. Del ostracismo a la modernidad, Madrid, Marcial Pons, 2004.

Cuerdo, Miguel, «Evaluación de los Planes Energéticos Nacionales en España (197585)», Revista de Historia Industrial, 15, Barcelona 1999, 161-178.

De la Torre, Joseba y García Zúñiga, Mario, Entre el mercado y el estado. Los planes de desarrollo durante el franquismo, Pamplona, Universidad Pública de Navarra, 2009.

De la Torre, Joseba y Rubio, Mar, «Nuclear Power for a Dictatorship: State and Business involvement in the Spanish Atomic Program», Journal of Contemporary History, 51, Barcelona 2015, 385-411.

Deniau, Jean-François, Mémoires de 7 vies. Tome 2: Croiser et Oser, Paris, Plon, 1997.

Díaz, Mario P. y Martínez-Vasseur, Pilar (coords.), La imagen de España y Francia en los medios de comunicación, Cáceres, Universidad de Extremadura, 2003.

Étienvre, Jean-Pierre y Urquijo, José Ramón (eds.), España, Francia y la Comunidad Europea, Madrid, Casa de Velázquez/CSIC, 1989.

Fernández de Sevilla, Tomàs, El desarrollo de la industria del automóvil en España: el caso de FASA-Renault, 1951-1985, Tesis Doctoral, Universitat de Barcelona, 2013.

Fraga, Manuel, En busca del tiempo servido, Barcelona, Planeta, 1987. 
García Delgado, José Luis (dir.), Economía española en la transición y la democracia (1973-1986), Madrid, Centro de Investigaciones Sociológicas, 1990.

García Ruiz, José Luis, «Cultural resistance and the gradual emergence of moderns marketing and retailing practices in Spain, 1950-1975», Business History, 49/3, Cambridge 2007, 367-384.

Gillespie, Richard, Rodrigo, Fernando y Story, Jonathan (eds.), Las relaciones exteriores de la España democrática, Madrid, Alianza, 1995.

Giscard d'Estaing, Valéry, L'État de la France, Paris, Fayard, 1981.

Giscard d'Estaing, Valéry, Le pouvoir et la vie, Paris, Librairie Generale Française, 2004.

González-Gómez del Miño, Paloma, La heterogeneidad de las relaciones bilaterales hispano-francesas durante el cambio politico español, 1969-1986. Sus constantes y sus variables, Tesis Doctoral, Universidad Complutense de Madrid, 1991.

Guirao, Fernando, «The European Community's Role in Promoting Democracy in Franco's Spain, 1970-1975», en Van der Harst, J. (ed.), Beyond the Customs Union: The European Community's Quest for Deepening, Widening and Completion, 1969-1975, Bruxelles, Bruylant, 2007; 161-193.

Hernández Andreu, Juan, Economía política de la transición en España (1973-1980), Madrid, Editorial Complutense, 2004.

Jacob, James E., Hills of conflict: Basque nationalism in France, Reno, University of Nevada, 1994.

Jeanneney, Jean-Marcel (dir.), L'Économie française depuis 1967: la traversée des turbulences mondiales, Paris, Seuil, 1989.

Jiménez, Juan Carlos, De Suárez a Zapatero: la política exterior de la España democrática, Madrid, Sílex, 2006.

Jiménez, Juan Carlos, España y Portugal en transición. Los caminos a la democracia en la peninsula ibérica, Madrid, Sílex, 2009.

Lemus, Encarnación y Pereira, Juan Carlos, «Transición y política exterior, 19751986», en Pereira, J.C. (coord.), La politica exterior de España. De 1800 hasta hoy, Barcelona, Ariel, 2010; 659-685.

Lemus, Encarnación, «Entre la intervención y la supervisión. Las potencias occidentales ante el cambio político peninsular», en Quirosa-Cheyrouze, R. (coord.), Historia de la transición en España: los inicios del proceso democratizador, Madrid, Biblioteca Nueva, 2007; 369-380.

Lemus, Encarnación, «Las posiciones francesas ante la desaparición de Franco y el establecimiento de la monarquía», Historia del Presente, 6, Madrid, 2005, 61-84.

Lemus, Encarnación, En Hamelin. La transición española más allá de sus fronteras, Madrid, Septem, 2002.

Lemus, Encarnación, Estados Unidos y la Transición española. Entre la Revolución de los Claveles y la Marcha Verde, Madrid, Sílex, 2011.

Lévy-Leboyer, Maurice (dir.), L'économie française dans la compétition internationale au $X X^{e}$ siècle, Paris, Comité pour l'Histoire Économique et Financière de la France, 2006.

Lhermie, Christian, Carrefour ou l'invention de l'hypermarché, Paris, Vuibert, 2003. 
López Rodó, Laureano, Memorias. 4. Claves de la Transición, Barcelona, Plaza y Janés, 1993.

Luis, Jean-Philippe y Niño, Antonio (coords.), Répresentations de l'autre et relations internationales. France-Espagne, $X I X^{e}-X X^{e}$ siècles, número monográfico de la revista Siècles, 20, 2004.

Maixé-Altés, Joan Carles, «La modernización de la distribución alimentaria en España, 1947-1955», Revista de Historia Industrial, 41/3, Barcelona 2009, 109-144.

Mansvelt-Beck, Jan, Territory and terror: conflicting nationalisms in the Basque Country, London-New York, Routledge, 2005.

Martín García, Óscar José y Ortiz Heras, Manuel (coords.), Claves internacionales en la transición española, Madrid, Los Libros de la Catarata, 2010.

Martín García, Óscar, «Emisarios de la Moderación. La diplomacia pública británica ante el fin de las dictaduras ibéricas», Hispania, LXXII/242, Madrid 2010, 789816.

Martínez-Vasseur, Pilar, «La imagen de España en Francia: de la Carmen de Merimée a las chicas de Almodóvar», Revista de Extremadura, 24, 1997, 57-90.

Mestres, Laia, «Veinte años de cooperación entre España y Francia: ¿amigos, socios o aliados?», Revista CIDOB d'Afers Internacionals, 75, 2006, 151-172.

Ministerio de Comercio, Dirección General de Aduanas, Estadísticas del comercio exterior de España, Madrid, Ministerio de Comercio, varios años.

Mitterrand, François, Réflexions sur la politique extérieure de la France, Paris, Fayard, 1986.

Morán Blanco, Sagrario, ETA entre España y Francia, Madrid, Ed. Complutense, 1997.

Morán López, Fernando, España en su sitio, Barcelona, Plaza y Janés, 1990.

Moreno, Antonio, «Por fin Europa: la transición y el camino hacia la adhesión a la CEE», en Forner, S. (ed.), Coyuntura Internacional y política española (18982004), Madrid, Biblioteca Nueva/Universidad de Alicante, 2010; 177-200.

Moruzzi, Jean-François y Boulaert, Emmanuel, Iparraterrak: separatisme et terrorisme en pays basque français, Paris, Plon, 1988.

Muñoz Guarasa, Marta, La inversión extranjera directa extranjera en España: factores determinantes, Madrid, Cívitas, 1999.

Muñoz Sánchez, Antonio, El amigo alemán: el SPD y el PSOE de la dictadura a la democracia, Barcelona, RBA, 2012.

Nadal, Jordi, Carreras, Albert y Sudrià, Carles (eds.), La economía española en el siglo XX, Barcelona, Ariel, 1987.

Nuñez Peñas, Vanessa, Entre la reforma y la ampliación (1976-1986). Las negociaciones hispano-comunitarias en tiempos de transición y "approfondissement», Tesis Doctoral, Universidad Complutense de Madrid, 2013.

Ortuño, Pilar, Los socialistas europeos y la transición española, Madrid, Marcial Pons, 2005.

Pardo, Rosa, «EEUU y el tardofranquismo: las relaciones bilaterales durante la presidencia de Nixon, 1969-1974», Historia del Presente, 6, 2005, 11-42. 
Pellistrandi, Benoît, «La imagen de España en Francia en el siglo XX», en Morales, A. (coord.), Las claves de España en el siglo XX, Madrid, Sociedad Estatal España Nuevo Milenia, 2001; 91-103.

Pereira Juan Carlos, «El factor internacional en la transición española: la influencia del contexto internacional y el papel de las potencias centrales», Studia Historica. Historia Contemporánea, 22, 2004, 185-224.

Pereira, Juan Carlos, «Transición y política exterior: el nuevo reto de la historiografía española», Ayer, 42, 2001, 97-123.

Pero, Mario del; Gavín, Víctor; Guirao, Fernando y Varsori, Antonio, Democrazie. L'Europa meridionale e la fine delle dittadure, Firenze, Le Monnier, 2010.

Pinilla, Alfonso, Ideología e información: la prensa francesa ante la muerte de Franco, Cáceres, Universidad de Extremadura, 2013.

Piñuel, José Luis, El terrorismo en la transición española (1972-1982), Madrid, Fundamentos, 1986.

Powell, Charles y Jiménez, Juan Carlos (eds.), Del autoritarismo a la democracia. Estudios de política exterior española, Madrid, Sílex, 2007.

Powell, Charles, «España en Europa: de 1945 a nuestros días», Ayer, 49, 2003: 81-119.

Powell, Charles, «International Aspects of Democratization: The Case of Spain», en Whitehead, L. (ed.), The International Dimensions of Democratization: Europe and the Americas, Oxford, Oxford University Press, 2001; 285-314.

Powell, Charles, «La dimensión exterior de la transición española», Revista del Centro de Estudios Constitucionales, 18, 1994, 79-116.

Powell, Charles, El amigo americano. España y Estados Unidos: de la dictadura a la democracia, Barcelona, Galaxia Guttenberg, 2011.

Powell, Charles, España en democracia, 1975-2000, Barcelona, Plaza \& Janés, 2001.

Puig, Núria y Castro, Rafael, «Patterns of Internacional Investiment in Spain, 18502005», Business History Review, 83, 2009, 505-537.

Puig, Núria, Álvaro, Adoración y Castro, Rafael, «Las empresas multinacionales extranjeras en España», en F. Ribera (ed.), Los números uno en España, Barcelona, Dobleerre, 2008; 19-45.

Rodríguez, Francisco J., Delgado, Lorenzo y Cull, Nicholas J., US Public Diplomacy and Democratization in Spain. Selling democracy?, New York, Palgrave, 2015.

Sánchez, Esther M., «French Military Action in Spain from Dictatorship to Democracy: Selling Arms, Transferring Technology, Approaching French and Spanish Armies», Journal of Contemporary History, 50, Cambridge 2015: 376-399.

Sánchez, Esther M., «La connexió hispano-francesa: intercanvis d'energia elèctrica i cooperació nuclear, c. 1950-1990», Recerques, 61, Barcelona 2010a, 101-136.

Sánchez, Esther M., «La implantación industrial de Renault en España: los orígenes de FASA-Renault, 1950-1970», Revista de Historia Económica, 22/1, Madrid 2004, 147-175.

Sánchez, Esther M., «The French Armament Firms and the Spanish Market, 194875», Business History, 52/3, Cambridge 2010b, 435-452. 
Sánchez, Esther M., Rumbo al Sur. Francia y la España del desarrollo, 1958-1969, Madrid, CSIC, 2006.

Sanz, Carlos, «La República Federal de Alemania ante el fin de las dictaduras ibéricas (1974-1976): miradas entrecruzadas», Hispania, LXII/242, 2012, 755-788.

Sartorius, Nicolás y Sabio, Alberto, El final de la dictadura. La conquista de la democracia en España (Noviembre de 1975-Junio de 1977), Madrid, Temas de Hoy, 2007.

Serrano, José María, «Crisis económica y transición política», Ayer, 15, 1994, 135-164.

Serrano, José María, De la crisis económica en España y sus remedios, Zaragoza, Prensas Universitarias de Zaragoza, 2011.

Soto, Álvaro y Mateos, Abdón (dirs.), Historia de la época socialista. España: 19821996, Madrid, Sílex, 2013.

Soto, Álvaro, Transición y cambio en España, 1975-1996, Madrid, Alianza, 2005.

Stockholm International Peace Research Institute [SIPRI], SIPRI Database, Stockholm, SIPRI, 1950-1986.

Tascón, Julio (ed.), La inversión extranjera en España, Madrid, Minerva, 2008.

Trouvé, Matthieu, L'Espagne et l'Europe. De la dictature de Franco à l'Union Européenne, Bruselas, PIE Peter Lang, 2008.

Trouvé, Matthieu, «François Mitterrand et l'Espagne (1981-1995)», Matériaux pour l'Histoire de Notre Temps, 101/102, París 2011, 17-19.

Tusell, Javier y Soto, Álvaro (eds.), Historia de la transición, 1975-1986, Madrid, Alianza Editorial, 1996.

Viñas, Ángel, En las garras del águila: los pactos con Estados Unidos, de Francisco Franco a Felipe González (1945-1995), Barcelona, Crítica, 2003.

Vorms, Charlotte y Aguilar, Miguel Ángel, 1983-2003. Veinte años de diálogo hispano-francés/Vingt ans de dialogue franco-espagnol, Madrid, Asociación Diálogo, 2003.

Recibido: $23 / 07 / 2014$

Aprobado: 20/12/2015 